\title{
Wasp Venom Biochemical Components and Their Potential in Biological Applications and Nanotechnological Interventions
}

\author{
Aida Abd El-Wahed ${ }^{1,2}$, Nermeen Yosri ${ }^{2,3}$, Hanem H. Sakr ${ }^{4}$, Ming Du ${ }^{5}\left(\mathbb{D}\right.$, Ahmed F. M. Algethami ${ }^{6}$, \\ Chao Zhao ${ }^{7,8} \oplus$, Ahmed H. Abdelazeem ${ }^{9,10}{ }^{\oplus}$, Haroon Elrasheid Tahir ${ }^{3}$, Saad H. D. Masry ${ }^{11,12}$, \\ Mohamed M. Abdel-Daim ${ }^{13}{ }^{(D}$, Syed Ghulam Musharraf ${ }^{14}$, Islam El-Garawani ${ }^{4}{ }^{(}$, Guoyin Kai ${ }^{15}{ }^{\circ}$, \\ Yahya Al Naggar ${ }^{16,17}$, Shaden A. M. Khalifa ${ }^{18, *}$ and Hesham R. El-Seedi ${ }^{2,18,19,20, *}$
}

1 Agricultural Research Centre, Department of Bee Research, Plant Protection Research Institute, Giza 12627, Egypt; aidaabd.elwahed@arc.sci.eg

2 Department of Chemistry, Faculty of Science, Menoufia University, Shebin El-Kom 32512, Egypt; nermeen.yosri@science.menofia.edu.eg

3 School of Food and Biological Engineering, Jiangsu University, Zhenjiang 212013, China; haroona28@yahoo.com

4 Department of Zoology, Faculty of Science, Menoufia University, Shebin El-Kom 32512, Egypt; hanem.sakr@science.menofia.edu.eg (H.H.S.); dr.garawani@science.menofia.edu.eg (I.E.-G.)

5 National Engineering Research Center of Seafood, School of Food Science and Technology, Dalian Polytechnic University, Dalian 116034, China; duming@dlpu.edu.cn

6 Alnahalaljwal Foundation Saudi Arabia, P.O. Box 617, Al Jumum 21926, Makkah, Saudi Arabia; ahmed@alnahalaljwal.com.sa

check for updates

Citation: Abd El-Wahed, A.; Yosri, N.; Sakr, H.H.; Du, M.; Algethami, A.F.M.; Zhao, C.; Abdelazeem, A.H.; Tahir, H.E.; Masry, S.H.D.;

Abdel-Daim, M.M.; et al. Wasp Venom Biochemical Components and Their Potential in Biological Applications and Nanotechnological Interventions. Toxins 2021, 13, 206. https://doi.org/10.3390/ toxins13030206

Received: 6 February 2021

Accepted: 8 March 2021

Published: 12 March 2021

Publisher's Note: MDPI stays neutral with regard to jurisdictional claims in published maps and institutional affiliations.

Copyright: (c) 2021 by the authors. Licensee MDPI, Basel, Switzerland. This article is an open access article distributed under the terms and conditions of the Creative Commons Attribution (CC BY) license (https:/ / creativecommons.org/licenses/by/ $4.0 /)$.
7 College of Food Science, Fujian Agriculture and Forestry University, Fuzhou 350002, China; zhchao@live.cn

8 State Key Laboratory of Quality Control in Chinese Medicine, Institute of Chinese Medical Sciences, University of Macau, Taipa, Macau, China

9 Department of Medicinal Chemistry, Faculty of Pharmacy, Beni-Suef University, Beni-Suef 62514, Egypt; ahmed.abdelazeem@pharm.bsu.edu.eg

10 Department of Pharmaceutical Sciences, College of Pharmacy, Riyadh Elm University, Riyadh 11681, Saudi Arabia

11 Abu Dhabi Food Control Authority, Al Ain 52150, United Arab Emirates; saad.masry@adafsa.gov.ae

12 Department of Plant Protection and Biomolecular Diagnosis, Arid Lands Cultivation Research Institute (ALCRI), City of Scientific Research and Technological Applications, New Borg El-Arab City, Alexandria 21934, Egypt

13 Pharmacology Department, Faculty of Veterinary Medicine, Suez Canal University, Ismailia 41522, Egypt; abdeldaim.m@vet.suez.edu.eg

14 International Center for Chemical and Biological Sciences, H.E.J. Research Institute of Chemistry, University of Karachi, Karachi 75270, Pakistan; musharraf@iccs.edu

15 Laboratory of Medicinal Plant Biotechnology, College of Pharmacy, Zhejiang Chinese Medical University, Hangzhou 310053, China; kaiguoyin@163.com

16 General Zoology, Institute for Biology, Martin Luther University Halle-Wittenberg, Hoher Weg 8, 06120 Halle (Saale), Germany; yehia.elnagar@science.tanta.edu.eg

17 Zoology Department, Faculty of Science, Tanta University, Tanta 31527, Egypt

18 Department of Molecular Biosciences, Stockholm University, the Wenner-Gren Institute, SE-106 91 Stockholm, Sweden

19 International Research Center for Food Nutrition and Safety, Jiangsu University, Zhenjiang 212013, China

20 Division of Pharmacognosy, Department of Pharmaceutical Biosciences, Uppsala University,

Biomedical Centre, P.O. Box 574, 75123 Uppsala, Sweden

* Correspondence: shaden.khalifa@su.se (S.A.M.K.); hesham.elseedi@su.se (H.R.E.-S.); Tel.: +46-700-43-43-43 (H.R.E.-S.)

Abstract: Wasps, members of the order Hymenoptera, are distributed in different parts of the world, including Brazil, Thailand, Japan, Korea, and Argentina. The lifestyles of the wasps are solitary and social. Social wasps use venom as a defensive measure to protect their colonies, whereas solitary wasps use their venom to capture prey. Chemically, wasp venom possesses a wide variety of enzymes, proteins, peptides, volatile compounds, and bioactive constituents, which include phospholipase A2, antigen 5, mastoparan, and decoralin. The bioactive constituents have anticancer, antimicrobial, and anti-inflammatory effects. However, the limited quantities of wasp venom and the scarcity of advanced strategies for the synthesis of wasp venom's bioactive compounds remain a challenge 
facing the effective usage of wasp venom. Solid-phase peptide synthesis is currently used to prepare wasp venom peptides and their analogs such as mastoparan, anoplin, decoralin, polybia-CP, and polydim-I. The goal of the current review is to highlight the medicinal value of the wasp venom compounds, as well as limitations and possibilities. Wasp venom could be a potential and novel natural source to develop innovative pharmaceuticals and new agents for drug discovery.

Keywords: wasp's venom; biomedical properties; bioactive compounds; nanotechnology applications; allergy

Key Contribution: Here, we critically review the biological properties of wasp venom and its components and their application in nanotechnology.

\section{Introduction}

Vespid wasps (Family: Vespidae) are distributed worldwide and comprise more than 5000 species. Wasp venom has a wide variety of chemical constituents, which includes proteins, peptides (e.g., mastoparan, eumenitin, eumenitin-R, rumenitin-F, EpVP, decoralin, and anoplin), enzymes (hyaluronidase, $\alpha$-glucosidase, phosphatase phospholipase A2, and phospholipase B), and small molecules [1-3]. The isolated compounds from wasp venom have shown several beneficial activities such as antimicrobial [4,5], anticancer [6], and antiinflammatory effects [7]. However, their peptides have been presented in trace quantities. Solid phase peptides synthesis (SPPS) was attributed to the design and development of these molecules [8]. Successfully, several peptides and their analogues were synthesized via SPPS technology such as mastoparan [9], anoplin [10], decoralin [11], polybia-MP-I [12], polybia-CP [13,14], polydim-I [15], and agelaia-MP [16]. The synthetic peptides have antimicrobal, and anticancer properties $[17,18]$.

The nests and venoms of wasps have been their role in the synthesis of nanoparticles of gold and silver tested. These nanoparticles were proven effective as antimicrobial and anticancer entities against a variety of microorganisms and cancer cells [19-21].

Despite preliminary medicinal outcomes, the interaction between wasp venom and human organs is still under debate. Wasp venom impacts the physiological aspects of the human body and could also lead to an allergic reaction [22].

Allergic reaction to wasp venom is a devastating problem due to the progressing immune responses of different systems. For instance, Vespa velutina venom administration lead to the failure of multi-organisms and even death among the Chinese population; and that was mostly due to toxins that are usually known to cause pain, inflammation, kidney and liver failure, cardiac arrhythmia, and sometimes neurotoxicity. Thus, many efforts are being invested into combating the allergic reactions and improving life quality using venom immunotherapy (VIT) [23]. VIT is the most effective method known so far for the avoidance of the systemic sting reactions even after discontinuation of the therapy [24].

This review attempts to shed light on the biochemical properties and potential applications of wasp venom. Previous studies have suggested that venom peptides could contribute to biological activities, such as anticancer, antimicrobial, neuroprotective, antiinflammatory, and antioxidant effects. It is important to investigate the components of venom to learn how the underlying defensive mechanisms have evolved since evidence suggests that the wasp venom can differ internally and interspecifically from other types of venom. Isolation and characterization of the venom components are essential steps in understanding the envenoming process [25]. 


\section{Biological Properties of Wasp Venom, and Their Isolated and Synthesized Bioactive Peptides}

\subsection{Biological Properties}

Studies have been conducted on venomous wasp structures, and their mode of action dating back to over 50 years ago. However, the therapeutic value of these toxins remains relatively unexplored. Further experiments are needed to fill the gap, and implementat quality control to elucidate wasp venom biological properties. As shown below, wasp venom exhibits biological properties, including antimicrobial, anticoagulant, genotoxic, and anti-inflammatory properties (Figure 1) [26-29].
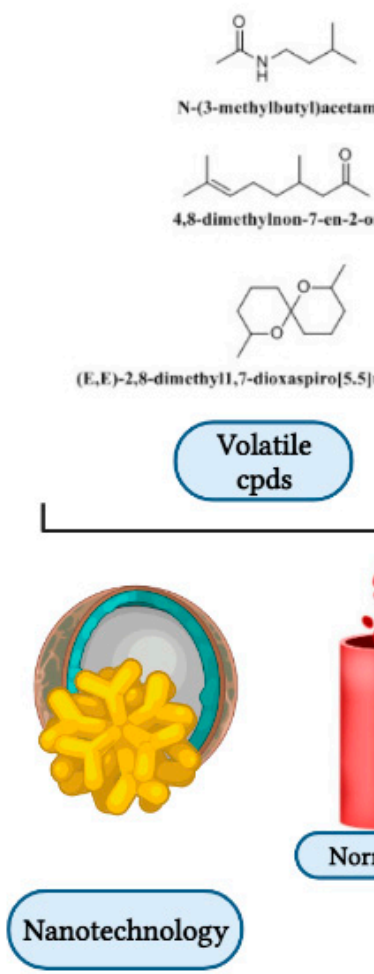

-(3-methylbutyl)aeetamide
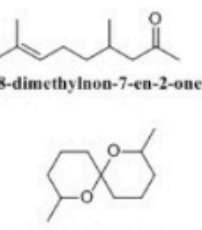

Volatile

cpds
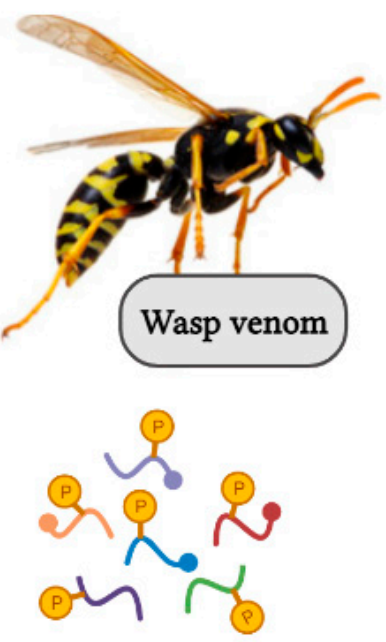

Peptides
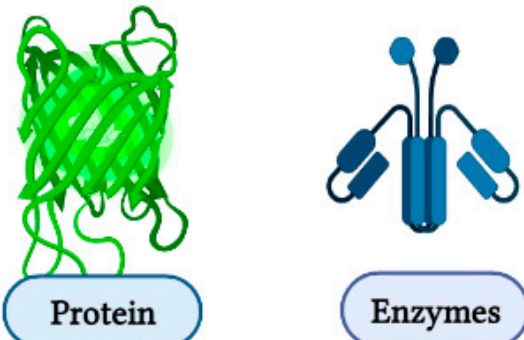

Enzymes

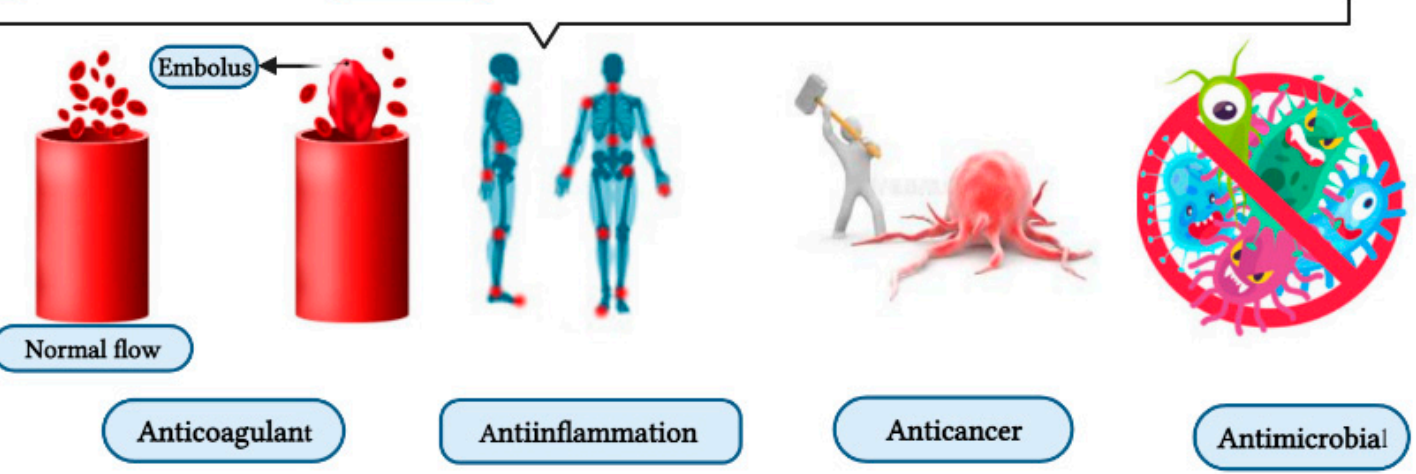

Figure 1. Wasp venom as a source of bioactive compounds and its biological activities and application.

\subsubsection{Antimicrobial Activities}

Today, microbial infections are a significant human concern globally. The emergence of infectious diseases and the scarcity of vaccines pose a significant danger to human health; thus, there is an immediate need to develop new antimicrobial agents [30]. Vespa orientalis's crude venom contains peptides and proteins. The venom has antimicrobial activity against Gram-positive and Gram-negative bacteria at very low concentrations relative to tetracycline (positive control). The inhibition zones were 10.2, 12.6, 22.4, and $22.7 \mathrm{~mm}$ for Klebsiella pneumonia, Staphylococcus aureus, Escherichia coli, and Bacillus subtilis, respectively, while MIC values were $128,64,64$, and $8 \mu \mathrm{g} / \mathrm{mL}$, respectively. The $\mathrm{MIC}_{50}$ and MIC $_{90}$ values were 74.4 and $119.2 \mu \mathrm{g} / \mathrm{mL}$ for K. pneumonia, 63.6 and $107 \mu \mathrm{g} / \mathrm{mL}$ for S. aureus, 45.3 and $65.7 \mu \mathrm{g} / \mathrm{mL}$ for E. coli, and 4.3 and $7.0 \mu \mathrm{g} / \mathrm{mL}$ for B. subtilis, respectively [31]. Previous studies have determined that the venom from Parischnogaster, Liostenogaster, Eustenogaster, and Metischnogaster wasps inhibited the development of Gram-positive B. subtilis, Gram-negative E. coli, and Saccharomyces cerevisiae yeast [32]. The peptide 
mastoparan-c, derived from Vespa crabro venom, triggered antimicrobial action toward resistant strains of S. aureus (Gram-positive) bacteria [26].

\subsubsection{Anti-Inflammatory Activities}

Inflammation is an underlying cause of several destructive disorders such as arthritis, cancer, and asthma. Anti-inflammatory medications are currently used to suppress shortand long-term body responses, and thus, it is vital to recognize new molecules with similar properties [33]. Vespa tropica venom effectively reduced oxidative stress and stimulated microglia via lipopolysaccharides (LPS) release. Wasp venom treatment (5 and $10 \mu \mathrm{g} / \mathrm{mL}$ ) greatly attenuated LPS induced activation of NF-kB phosphorylation [34]. Bracon hebetor venom (BHV) affected LPS-induced nitric oxide (NO) in RAW 264.7 cells and septic shock in mouse models. BHV strongly mediated LPS-induced inflammation without any cytotoxicity at a concentration of $0.1-0.4 \mu \mathrm{g} / \mathrm{mL}$ [35]. Moreover, Nasonia vitripennis venom contains at least 80 proteins, and it exerts anti-inflammatory impacts via down-regulation of the proinflammatory cytokine IL-1 $\beta$ [27].

\subsubsection{Genotoxicity}

Polybia paulista wasp venom concentrations below $0.01-10 \mu \mathrm{g} / \mathrm{mL}$ did not cause cytotoxicity and showed genotoxic and mutagenic potential in HepG2 cells. The genotoxic and mutagenic behavior of $P$. paulista venom could be explained by the action of phospholipase, mastoparan, and hyaluronidase, leading to cell membrane disruption and genetic material alterations or even DNA mutations [29].

\subsubsection{Anticoagulant}

The venom of Polybia occidentalis, a social wasp, has anticoagulant, and fibrinogendegrading pharmacological properties. Anticoagulation occurs at different stages of the clotting process (intrinsic, extrinsic, and specific pathway). Venom can inhibit platelet aggregation and destroy plasma fibrinogens [28].

\subsection{Isolated and Synthesized Bioactive Peptides from Wasp Venoms}

Wasp venoms are cocktails of peptides, proteins, and small organic molecules like volatiles compounds (Figures 1 and 2), where peptides are the most abundant compounds, as mentioned in Table 1 [36,37]. The minute quantity of extracted venom stands as a hindrance to the analysis and understanding of the pharmacological, biological, and ecological aspects of the venom constituents. Here, we discuss the isolated peptides from wasp venom and their chemical design via SPPS [8].<smiles>C=CCCCCCC(C)=O</smiles>

Non-8-en-2-one (A)<smiles>CCCCCCCC(C)=O</smiles>

Nonan-2-one (D)<smiles>CCCCCC(C)=O</smiles>

Heptan-2-one (B)<smiles>CC(=O)NCCC(C)C</smiles>

N-(3-methylbutyl)acetamide (C)<smiles>CC(=O)CC(C)CCC=C(C)C</smiles>

4,8-dimethylnon-7-en-2-one (E)<smiles>CCCCCCCCCC(C)=O</smiles>

undecan-2-one (F)<smiles>CC1CCCC2(CCCC(C)O2)O1</smiles>

(E,E)-2,8-dimethyl1,7-dioxaspiro[5.5] undecane (G)

Figure 2. Some of the volatile compounds identified from wasp venom. 


\subsubsection{Mastoparans}

The mastoparans are comprised of a class of peptides isolated from Vespula lewisii [38], V. crabro [26], Vespula vulgaris [4], and Polistes jadwigae [39]. Mastoparans are characterized by their antitumor activity against melanoma cells (B16F10-Nex2) [38].

\section{Mastoparan (MP)}

Mastoparan (MP), a major component of $P$. jadwigae wasp venom, is a basic amphiphilic $\alpha$-helical peptide that consists of 14 amino acid residues, hydrophobic and essential amino acids, and an amino acid C-terminus, as shown in Table 1 [39]. These characters are specific for the cationic amphiphilic peptide (CAP) class and favour the $\alpha$-helix conformation while in contact with bilayer phospholipids [40]. MP has several biological effects and has shown antimicrobial properties [41], increased histamine release from mast cells [42], and cytotoxicity effect on tumor cells [18]. MP-induced mitochondrial permeability and powerful transition of mitochondrial permeability (PT) in a range of $25 \mu \mathrm{M}$ in a homogeneous K562 cell are reported [43]. Moreover, MP exerts anticancer activities toward leukemia, myeloma, and breast cancer cells. In a mouse model of mammary carcinoma, MP and gemcitabine (drug) worked synergistically [18]. MP was active on a dose-dependent basis with doses ranging from 77.9 to $432.5 \mu \mathrm{M}$ against human cancer cells (A2058 (melanoma), SiHa (cervical carcinoma), Jurkat (T cell leukemia), MCF-7, MDAMB-231, and SK-BR-3 (breast cancer). The $\mathrm{IC}_{50}$ of B16F10 murine melanoma was $165 \mu \mathrm{M}$. MP-induced apoptosis involves activation of caspase $-9,-12$, and -3 , PARP cleavage, upregulation of pro-apoptotic Bax, and Bim, down-regulation of anti-apoptotic Bcl-XL; furthermore, cell apoptosis induced mitochondrial membrane disruption [38].

MP inhibited bradykinin-induced phosphoinositide hydrolysis within $5 \mathrm{~min}$ of administration at a concentration of $30 \mu \mathrm{M}$ and induced the release of prostaglandin E2 (PGE 2) in rabbit astrocytes within $10 \mathrm{~min}$ [44].

The synthetic peptide derived from MP is called mastoparan ([I5, R8] MP) and has a wide range of antimicrobial activities against bacteria and fungi at MIC values of 3-25 $\mu \mathrm{M}$ with no hemolytic or cytotoxic properties to the human embryonic kidney cell line (HEK293 cells). The synthesis does not appear to change the $\alpha$-helical conformation but enhances the biological activity [45]. Ten MP derivatives have been synthesized via SPPS strategies and evolved against Acinetobacter baumannii. MP analogs (H-INIKALAALAKKII-NH ${ }_{2}$, H-INLKALAALAKKIL-CH $\mathrm{CH}_{2} \mathrm{NH}_{2}$, and Gu-INLKALAALAKKIL-NH $\mathrm{N}_{2}$ ) demonstrated the same behavior against $A$. baumannii as the original peptide $(2.7 \mu \mathrm{M})$ and retained its consistency in the presence of human serum for more than $24 \mathrm{~h}$ [9]. Three MP analogs, MK4589 (INWKKIAKKVAGML-NH ${ }_{2}$ ), MK45789 (INWKKIKKKVAGM), and MK4578911 (INWKKIKKKVKGML-NH ${ }_{2}$ ), were synthesized, and exhibited strong antibacterial properties against Gram-negative bacteria compared to the reference antibiotic, chloramphenicol [46]. Mastoparan-V1 (MP-V1), a de novo type of V. vulgaris venom mastoparan, has higher anti-Salmonella activity than other mastoparans [4]. MP analog peptides showed activity against Candida albicans, with low cytotoxicity and non-teratogenicity using cell cultures and zebrafish models [47]. Synthetic MP-V1 has antimicrobial properties at MICsvalues of 106.95, 56.86, and $123 \mu \mathrm{g} / \mathrm{mL}$ against Salmonella Gallinarum, S. typhimurium, and S. enteritidis, respectively [48].

\section{Mastoparan-B (MP-B)}

Mastoparan-B (MP-B), the mastoparan homolog of Vespa basalis venom, has a less hydrophobic amino acid sequence with four lysines (LKLKSIVSWAKKVL-NH ${ }_{2}$ ) [49] and is approved as a cardiovascular depressor [50] and antibacterial agent [51]. MP-B shows powerful hemolytic activity secondary to the stimulation of histamine release from rat peritoneal mast cells [49]. A synthetic MP-B analog (LDLKSIVSWAKKVL-NH $\mathrm{H}_{2}$ ), in which lysine was replaced by asparagine at position 2 , showed a remarkable decline of cardiovascular depressors; in contrast, the analog with leucine replacing lysine at position 4,11, or 12 (LKLLSIVSWALLVL-NH ${ }_{2}$ ) did not display the same effect [50]. 


\section{Mastoparan-M}

Mastoparan-M is an amphipathic tetradecapeptide toxin and a vespid venom mastoparan counterpart isolated from the Vespa mandarinia hornet in Japan. Mastoparan-M has the (INLKAIAALAKKLL) sequence. At a minimum concentration (MIC) of $0.5 \mathrm{nmol} / \mathrm{mL}$, the peptide degranulated rat peritoneal mast cells [52]. Mast cell degranulation induced the release of inflammatory mediators, such as TNF- $\alpha$, IL- $1 \beta$, and nitrite, from cultured mouse spleen macrophages [53].

SPPS was used to synthesize D-mastoparan M (INLKAIALAKKLL) and L-mastoparan M (INLKAIAALAKKLL). D-mastoparan M showed MIC of $6.25 \mathrm{mg} / \mathrm{L}$ against $E$. coli and Pseudomonas aeruginosa and $3.12 \mathrm{mg} / \mathrm{L}$ against $S$. aureus. The antibacterial impact of Dmastoparan was twice as effective as L-mastoparan M. After the supplementation of D-mastoparan M, bacterial lysis was observed at $1 \mathrm{~h}$ and was completed after $4 \mathrm{~h}$ [54].

\subsubsection{Anoplin}

Anoplin (ANP) is the smallest antimicrobial, naturally occurring peptide isolated from the solitary spider wasp Anoplius samariensis (Hymenoptera: Pompillidae) and contains ten amino acids (Table 1), making it an ideal research template [55]. The peptide causes mast cell degranulation and has antimicrobial activity [55]. The presence of four-polar residues makes ANP water-soluble. Its interaction with amphipathic environments, such as trifluoroacetic acid (TFE)/water mixtures, or with anisotropic media, such as sodium dodecyl sulfate (SDS) micelles or anionic vesicles, induces $\alpha$-helical conformations and amphiphilic properties as indicated by the circular dichroism (CD) spectra [55]. ANP inhibited the proliferation of murine erythroleukemia (MEL) cells in a time- and dosedependent manner. The $\mathrm{IC}_{50}$ values were $161.49,121.03$, and $114.88 \mu \mathrm{M}$ at 24,48 , and $72 \mathrm{~h}$, respectively. Disrupting the cell membrane integrity was the primary mechanism behind anoplin's cytotoxicity [56].

Synthetic ANP peptides have a broad spectrum of antimicrobial activity against Grampositive and Gram-negative bacteria. ANP antimicrobial activity is susceptible to salt. Gram-negative bacteria were entirely immune to ANP in high-salt media $(150 \mathrm{mM} \mathrm{NaCl})$; however, Gram-positive bacteria's efficacy was greatly diminished [55]. Equally interesting, it stimulates rat peritoneal mast cell degranulation, and ANP's hemolytic activity was relatively low or virtually inactive on human erythrocytes [55].

ANP's activity is highly sensitive to minor changes of the primary structure, such as single amino acid mutations in certain positions. For example, 37 anoplin analogs have been synthesized by replacing single and multiple residues leading to a change in amphipathicity and charge. Accordingly, the effects against S. aureus and E. coli varied considerably depending on the hydrophobicity and position of the various replaced amines. Residue replacement at positions 5 , and 8 with phenylalanine or tryptophan caused by an increase in antibacterial, and hemolytic activity owed to the role of these aromatic residues in the membrane anchoring. Lysine placement in position 8 improved peptide selectivity for prokaryotic cells due to the higher charge [57], whereas C-and N-terminal truncation and C-terminus deamidation drastically decreased peptide antibacterial properties [58]. Antimicrobial activities were measured against $E$. coli and B. subtilis for all three derivatives of ANP (ANP-NH $\mathrm{N}_{2}$, D-ANP-NH $\mathrm{N}_{2}$, and ANP-OH). Both amidated ANP derivatives display $50 \mu \mathrm{g} / \mathrm{mL}$, MIC values for B. subtilis, and $100 \mu \mathrm{g} / \mathrm{mL}$ for E. coli. Alternatively, the deamidated form showed significantly lower bactericidal activity with MIC values of $200 \mu \mathrm{g} / \mathrm{mL}$. The $\mathrm{LD}_{50}$ values for both amidated ANP forms were identical and approximately 10- to 30fold lower than those of ANP-OH. ANP loses its biological activity after deamidation. Both amidated and carboxylated forms have secondary structures similar to those of the lytic ANP [59]. The natural cationic ANP was modified by substituting residues Gly1 for Lys or Arg, Arg ${ }^{5}$ for Phe, and $\mathrm{Thr}^{8}$ for Lys. The antimicrobial properties change dramatically, and high activity against Gram-negative bacterium Zymomonas mobilis at MIC $7 \mu \mathrm{g} / \mathrm{mL}$ was observed, compared to native peptide MIC $200 \mu \mathrm{g} / \mathrm{mL}$; additionally, it was non-toxic to erythrocytes and resistant to proteolysis [10]. Interestingly, the antimicrobial activities of 
ANP and analogs ANP-2 (WLLKRWKLL-NH ${ }_{2}$ ), and ANP-4 (KLLKWKKLL-NH ${ }_{2}$ ) were significantly higher than ANP-1 (WLLKRWKKLL-NH ${ }_{2}$ ) and ANP-3 (KLLKWWKKLL$\mathrm{NH}_{2}$ ). The highest antimicrobial activity against $B$. subtili was shown by ANP-2 and ANP-4 (MIC value: $4 \mu \mathrm{M}$ ) compared to the parent peptide (MIC value: $32 \mu \mathrm{M}$ ). ANP-4 treatment significantly reduced the mortality rate of mice infected with E. coli compared to ANP. ANP-4 is a novel analog of ANP with high antimicrobial activity and enzyme stability that represent it as a successful agent for infections treatment [60].

\subsubsection{Decoralin}

Decoralin $\left(\right.$ Dec- $\left.-\mathrm{NH}_{2}\right)$ is a peptide derived from the solitary Eumenine wasp (Oreumenes decoratus) [61] and was synthesized by solid-phase synthesis [62]. Equally important, a natural antimicrobial peptide, Dec- $\mathrm{NH}_{2}$, was isolated from wasp venom, and its synthetic derivatives were manufactured using peptide design. Dec- $\mathrm{NH}_{2}$ exhibits potent activity toward cancer cells at doses of $12.5 \mu \mathrm{mol} / \mathrm{L}$ and specific inhibition of MCF-7 breast cancer cells [62]. In a biological assessment, synthetic Dec- $\mathrm{NH}_{2}$ demonstrated strong broadspectrum antimicrobial activity, slight mast cell degranulation, and leishmanicidal activity. The peptide displayed low hemolytic function against mouse erythrocytes, $\mathrm{EC}_{50}$ lower $300 \mu \mathrm{M}$ [61]. A synthetic Dec- $\mathrm{NH}_{2}$ analog with C-terminal amidation demonstrated much more efficient activity against Gram-positive and Gram-negative bacteria and yeast. When isoleucine was substituted by phenylalanine residue at position 6 , the peptide increased its resistance to degradation in bovine fetal serum. Besides that, lower hemolytic activity was obtained for $[\mathrm{Pro}]^{4}$-decoralin- $\mathrm{NH}_{2}$ and $[\mathrm{Phe}]^{6}$-Des[Thr $]^{11}$-decoralin- $\mathrm{NH}_{2}$. The antimicrobial effect was increased in the case of $[\mathrm{Phe}]^{9}-[\mathrm{Phe}]^{10}-\mathrm{Dec}-\mathrm{NH}_{2}(\mathrm{MIC}=0.39$ vs. native peptide of $0.78 \mu \mathrm{mol} / \mathrm{L}$ ) against Micrococcus luteus A 270 [63]. Torres et al. synthesized two leucine-substituted Dec- $\mathrm{NH}_{2}$ analogs; [Leu ${ }^{8}$-Dec- $\mathrm{NH}_{2}$, and [Leu ${ }^{10}$-Dec$\mathrm{NH}_{2}$ using SPPS. [Leu $]^{10}$-Dec- $-\mathrm{NH}_{2}$ analog showed similar activity against $E$. coli, and $P$. aeruginosa (MIC $1.6 \mu \mathrm{mol} / \mathrm{L}$ ), and higher activities against M. luteus and C. albicans. The same helical structure of the [Leu $]^{8}-\mathrm{Dec}-\mathrm{NH}_{2}$ analog exhibited evidential low activities against M. luteus, E. coli, Salmonella arizonae, B. subtilis, P. aeruginosa, and C. albicans [11]. The natural sequence of amidated Dec- $\mathrm{NH}_{2}$ and eight synthesized analogs, along with their biological activity toward Plasmodium, were reviewed. The Dec- $\mathrm{NH}_{2}$ template compound did not display antiplasmodial properties; on the other hand, it's designed analogs showed significant antiplasmodial activity $(>95 \%)$. The highest antiplasmodial behavior was achieved by mutations made to the N-terminus of Dec [64].

\subsubsection{Polybia-MP-I}

Polybia-MP-I is one of the 14 amino acid residues (Table 1) of mastoparan peptides [65]. The peptide was derived from the venom of the social wasp P. paulista. It causes moderate mast cell degranulation, demonstrates chemotactic action for polymorphonuclear leukocytes, exhibits active antimicrobial activity, and is non-hemolytic to rat erythrocytes [66]. Polybia-MP-I is cytotoxic to leukemic T lymphocytes and strongly selective to these individual cells [67]. Polybia-MP-I has demonstrated antitumor action against bladder and prostate cancer [12]; however, this antitumor activity drastically decreased with the synthesized analogs (replacement of the amino acids at position 7, 8, or 9 with Pro residue). These substitutions influence the original helical structure and electrostatic equilibrium and increase the degree of peptide hydrophilic behavior $\left(\mathrm{Pro}^{7}\right.$ and $\left.\mathrm{Pro}^{9}\right)$. Polybia-MP-I exerts pore formation and thus alters the intact cellular structure leading to a cytotoxic and antiproliferative outcome. It can selectively inhibit the proliferation of prostate cancer cell lines (PC-3), human bladder cancer cell lines (Biu87 and EJ), and human umbilical vein endothelial cell lines (HUVEC) at $\mathrm{IC}_{50}$ of 20.8, 25.32, and $36.97 \mu \mathrm{M}$, respectively [12].

The peptides polybia-MP-I (IDWKKLLDAAKQIL-NH ${ }_{2}$ ) and Asn-2-polybia-MP-I (INWKKLLDAAKQIL-NH ${ }_{2}$ ) were manually synthesized in the solid phase. Polybia-MP-I and N-2-polybia-MP-I exhibited a significant reduction in the pain threshold at 30, and $50 \mu \mathrm{g} / 50 \mu \mathrm{L}$ as detected at 2 , and $8 \mathrm{~h}$ after peptide injection into the hind paw of mice $[68,69]$. 
The polybia-MP-I analogs (proline replacement) showed reduced antibacterial activity compared to the parent. MIC values of polybia-MP-I were 4,16, 16, and $32 \mu \mathrm{M}$ for B. subtilis, E. coli, S. epidermidis, and S. aureus, respectively. The MIC value was $8 \mu \mathrm{M}$ for C. glabrata versus $16 \mu \mathrm{M}$ against $C$. albicans. The fungicidal activity of polybia-MP-I versus both Candida glabrata and C. albicans was measured as an minimum fungicidal concentration (MFC) of $32 \mu \mathrm{M}[70,71]$.

\subsubsection{Polybia-CP}

Polybia-CP has been isolated from P. paulista, and gradually synthesized by SPPS, and its effects on bacteria have been recorded [14]. Polybia-CP's MICs for E. coli, P. aeruginosa, S. aureus, S. epidemic, and B. subtilis were $16,128,4,16$, and $4 \mu \mathrm{M}$, respectively, while the MBCs were $8,16,128$, and $16 \mu \mathrm{M}$, for B. subtilis, S. aureus, and E. coli, respectively. The peptide was stable at different temperature ranges of $20-100{ }^{\circ} \mathrm{C}$, and the temperature changes did not affect the MIC values [72]. Polybia-CP showed antimicrobial activities with MIC values of 4-64 $\mu \mathrm{M}$ in eight fungal strains, where the highest activity was noted against $C$. tropicalis at a MIC of $4 \mu \mathrm{M}$ [13].

Synthetic Polybia-CP has potent antitumor activity against Biu87 and PC-3 cell lines. Cell proliferation inhibition was observed at $\mathrm{IC}_{50}$ of 17.84 and $11.01 \mu \mathrm{M}$, respectively. The cytotoxicity of polybia-CP was explained by the disruption of cell membrane integrity [14].

\subsubsection{Polydim-I}

Polydim-I is a peptide derived from the venom of a neotropical wasp (Polybia dimorpha). The peptide contains 22 amino acid residues and is known for its amphipathic properties due to the presence of hydrophobic amino acid residues (e.g., methionine, leucine, valine, and proline) [15].

Polydim-I was synthesized with high quality (>99\%), and the relevant peptide sequence was tested and validated by MS analysis. The synthetic peptide is active against Mycobacterium abscessus subsp. massiliense infections as described in in vitro and in vivo studies. In vitro study, the inhibition was 55 to $68 \%$ of $M$. abscessus subsp massiliense strains growth at a concentration of $15.2 \mu \mathrm{g} / \mathrm{mL}$ in which the cell shape was expressively damaged. The peptide prevents bacterial growth through the inhibition of protein synthesis, did not result in visible morphological changes. Polydim-I treatment at $2 \mathrm{mg} / \mathrm{kg} / \mathrm{mLW}$ showed significant reduction of the bacterial load in in the lungs, spleen, and liver [15], and the antimicrobial properties against $S$. aureus, E. coli, Enterococcus faecalis, Acinetobacter calcoaceticus-baumannii were displayed with $\mathrm{MIC}_{50}$ values of $4.1,50.7,73.2$, and $84.0 \mu \mathrm{g} / \mathrm{mL}$, respectively [73].

\subsubsection{Protonectarina-MP and Agelaia-MP}

Protonectarina-MP was isolated from Protonectarina syleirae venom and is a member of the 14 amino residue class of mastoparans [74]. The peptide protonectarina-MP-NH ${ }_{2}$ (INWKALLDAAK KVL-NH ${ }_{2}$ ) and its analogue protonectarina-MP-OH (INWKALLDAAKKVL-OH) were produced by step-by-step manual SPPS. Protonectarin-MP- $\mathrm{NH}_{2}$ is a powerful mast cell degranulating peptide with slightly higher degranulating activity $\left(\mathrm{ED}_{50}=8 \times 10^{-5} \mathrm{M}\right)$ than the standard peptide $\left(\mathrm{ED}_{50}=20 \times 10^{-5} \mathrm{M}\right)$. Protonectarina-MP-OH, and even at high concentrations, has reduced degranulation activity. Protonectarina- $\mathrm{MP}-\mathrm{NH}_{2}$ has effective antimicrobial activity against both Gram-positive and Gram-negative bacteria, while protonectarina-MP-OH has much poorer antimicrobial activity [17].

Agelaia-MP is a mastoparan peptide that contains 14 residues (INWLKLGKAIIDAL$\mathrm{NH}_{2}$ ) and is isolated from the venom of the social wasp Agelaia pallipes. It was characterized by its poor antimicrobial action and the lack of chemotaxis toward mast cells [74]. Using the Fmoc strategy, agelaia-MP has been chemically and manually synthesized. At a concentration of $10 \mu \mathrm{M}$, the peptide enhances the insulin secretion from the mice pancreatic islets using different glucose doses $(2.8,11.1$, and $22.2 \mathrm{mM})$. In mouse models, agelaiaMP-I has a dose-dependent anti-nociceptive effect. For example, nociception significantly 
declined when the highest dosage $(6.4 \mathrm{nmol})$ was administered, while the maximal effect was observed $4 \mathrm{~h}$ after the peptide injection [16].

Protonectin is derived from the venom of the neotropical social wasp (Agelaia pallipes), with a sequence of ILGTILGLLKGL-NH ${ }_{2}$. The peptide exhibits poor hemolysis to rat erythrocytes [74]. Protonectin has some mast cell degranulating activity and potent antimicrobial action with E. coli, P. aeruginosa, B. subtilis, and S. aureus at MICs of 25, 1.7, 3.1, and $12.5 \mu \mathrm{g} / \mathrm{mL}$, respectively [74].

Protonectin and its three analogues were synthesized through a stepwise solid-phase assay by replacing L-proline. Proline is a unique amino acid among the 20 protein-forming amino acids because its amine nitrogen is linked to two groups of alkyls, making it a secondary amine. The insertion of proline inside the peptide considerably changes the secondary structure. Protonectin has demonstrated potent antibacterial action toward multidrug-resistant $S$. aureus, and E. coli at MICs of 8 , and $32 \mu \mathrm{M}$, respectively. MBC values were $8,8,16$, and $64 \mu \mathrm{M}$ for B. subtilis, S. epidermidis, S. aureus, and E. coli, respectively, indicating potent bactericidal effect [75].

\subsubsection{Philanthotoxin-433 (PhTX-433)}

Philanthotoxin-433 (PhTX-433) is a polyamine-based toxin isolated from Egyptian digger wasp (Philanthus triangulum) venom. The venom induces prey paralysis by suppressing nicotinic acetylcholine receptors (nAChRs) and ionotropic glutamate receptors (iGluRs). PhTX-433 is an important lead compound in neuropharmacology [76,77]. The action of 17 analogs of PhTX-343 against ganglionic $(\alpha 3 \beta 4)$ and brain $(\alpha 4 \beta 2) n A C h R s$ has been expressed in Xenopus oocytes. IC 50 values for PhTX-343 inhibition of $\alpha 3 \beta 4$ and $\alpha 4 \beta 2$ receptors were 7.7 and $80 \mathrm{nM}$, respectively [78]. Their total synthesis achieved good yield $(77 \%)$ and purity $(80 \%)$ using a mild borane reduction protocol of polyamide precursors to access the polyamine chains. The synthesis of PhTX-433 isomers proved this strategy's potential for the generation of branched analogs [76].

Table 1. Isolated constitutes from Wasp-Venom and their biological activity.

\begin{tabular}{|c|c|c|c|}
\hline Wasp-Scientific Name & Isolated Compounds & Biological Activity & Reference \\
\hline \multicolumn{4}{|c|}{ Peptides } \\
\hline $\begin{array}{l}\text { Vespa xanthoptera } \\
\text { Vespula lewisii }\end{array}$ & $\begin{array}{l}\text { Mastoparan (MPX) } \\
\text { (INWKGIAAMAKKLL-NH } 2 \text { ) }\end{array}$ & $\begin{array}{l}\text { Cytotoxic against Glioblastoma multiforme (T98G) } \\
\text { cell, } 60 \% \text { inhibition at } 20 \mu \mathrm{mol} / \mathrm{L} \text { (in vitro) } \\
\text { Anti-Escherichia coli and anti-Lactococcus lactis at MIC } \\
8 \text {, and } 2.5 \mu \mathrm{M} \text {, respectively (in vitro). }\end{array}$ & {$[40,79,80]$} \\
\hline $\begin{array}{l}\text { Anterhynchium } \\
\text { flavomarginatum micado }\end{array}$ & $\begin{array}{l}\text { Mastoparan-AF (EMP-AF) } \\
\left.\text { (INLLKIAKGIIKSL-NH }{ }_{2}\right)\end{array}$ & $\begin{array}{l}\text { Blocked lobster neuromuscular transmission. } \\
\text { Mediated depolarization of the muscle membrane, } \\
\text { often leading to a weak contraction of the muscle at } \\
0.1 \pm 1 \mathrm{mM} \text { (in vitro). }\end{array}$ & {$[1,81]$} \\
\hline
\end{tabular}

Induces apoptosis in B16F10-Nex2 melanoma cells

treated with $165 \mu \mathrm{M}$.

Potent anti-inflammatory.

Shows activity against colistin-susceptible

V. lewisii, Vespa tropica Mastoparan and Polybia paulista
(INLKALAALAKKIL)
Acinetobacter baumannii and colistin-resistant

Acinetobacter baumannii at $\mathrm{MIC}_{50}$ value of 4 , and

$8 \mathrm{mg} / \mathrm{L}$, respectively.

Antimicrobial activity on the epimastigote,

trypomastigote and amastigote forms of Trypanosoma

cruzi $Y$ strain via dose-dependent growth inhibition

(in vitro).

\begin{tabular}{lll}
\hline Vespa basalis & $\begin{array}{l}\text { Mastoparan B } \\
\text { (LKLKSIVSWAKKVL) }\end{array}$ & $\begin{array}{l}\text { Anti-Enterococcus faecalis and anti-Bucillus subtilis at } \\
\text { MIC of } 3.13 \mathrm{mg} / \mathrm{mL} \text { (in vitro). }\end{array}$ \\
\hline V. basalis & $\begin{array}{l}\text { Mastoparan-I1 } \\
\text { (INLKAIAALVKKVL) }\end{array}$ & ND \\
\hline
\end{tabular}


Table 1. Cont

\begin{tabular}{|c|c|c|c|}
\hline Wasp-Scientific Name & Isolated Compounds & Biological Activity & Reference \\
\hline V. basalis & $\begin{array}{l}\text { Mastoparan-A } \\
\text { (IKWKAILDAVKKVI) }\end{array}$ & ND & [51] \\
\hline V. basalis & $\begin{array}{l}\text { Mastoparan-T } \\
\text { (INLKAIAAFAKKLL) }\end{array}$ & ND & [51] \\
\hline Vespula vulgaris & $\begin{array}{l}\text { Mastoparan V1 } \\
\text { (INWKKIKSIIKAAMN) }\end{array}$ & $\begin{array}{l}\text { Potent antimicrobial activity against Streptococcus } \\
\text { mutans and Salmonella enterica at } 50 \mu \mathrm{M} \text { (in vitro). }\end{array}$ & [4] \\
\hline Vespa orientalis $L$. & $\begin{array}{l}\text { Mastoparan (HRI) } \\
\text { (INLKAIAALVKKVL-NH }{ }_{2} \text { ) }\end{array}$ & $\begin{array}{l}\text { Cytotoxic towards T98G cells and give } 80 \% \\
\text { inhibition at } 20 \mu \mathrm{mol} / \mathrm{L} \text { (in vitro). }\end{array}$ & {$[40]$} \\
\hline Vespa crabro & $\begin{array}{l}\text { Mastoparan-C (MP-C) } \\
\left(\text { LNLKALLAVAKKIL-NH }{ }_{2}\right)\end{array}$ & $\begin{array}{l}\text { Inhibition of the biofilm formation by Staphylococcus } \\
\text { Aureus and Pseudomonas aeruginosa at } 32 \mu \mathrm{M} \text { MBIC } \\
\text { (in vitro). }\end{array}$ & [26] \\
\hline V. tropica & $\begin{array}{l}\text { Mastoparan-VT1 } \\
\text { (INLKAIAALAKKLL) }\end{array}$ & Anti-E. faecalis at $2.5 \mu \mathrm{g} / \mathrm{mL}$ (in vitro). & {$[30]$} \\
\hline V. tropica & $\begin{array}{l}\text { Mastoparan-VT2 } \\
\text { (NLKAIAALAKKLL) }\end{array}$ & $\begin{array}{l}\text { Anti-E. faecalis, anti-E.coli and anti-S.aureus at } \\
5 \mu \mathrm{g} / \mathrm{mL} \text { (in vitro). }\end{array}$ & {$[30]$} \\
\hline V. tropica & $\begin{array}{l}\text { Mastoparan-VT3 } \\
\text { (INLKAITALAKKLL) }\end{array}$ & $\begin{array}{l}\text { Anti-S. aureus and anti-Candida parapsilosis at } \\
2.5 \mu \mathrm{g} / \mathrm{mL} \text { (in vitro). }\end{array}$ & {$[30]$} \\
\hline V. tropica & $\begin{array}{l}\text { Mastoparan-VT4 } \\
\text { (INLKAIAPLAKKLL) }\end{array}$ & $\begin{array}{l}\text { Anti-Bacillus pyocyaneus, anti-P. aeruginosa, and } \\
\text { anti-Bacillus dysenteriae at } 10 \mu \mathrm{g} / \mathrm{mL} \text { (in vitro). }\end{array}$ & [30] \\
\hline V. tropica & $\begin{array}{l}\text { Mastoparan-VT5 } \\
\text { (VIVKAIATLASKLL) }\end{array}$ & Anti-Candida albicans at $40 \mu \mathrm{g} / \mathrm{mL}$ (in vitro). & {$[30]$} \\
\hline V.tropica & $\begin{array}{l}\text { Mastoparan-VT6 } \\
\text { (INLKAIAALVKKLL) }\end{array}$ & $\begin{array}{l}\text { Anti-S. aureus and anti-B. dysenteriae at } 20 \mu \mathrm{g} / \mathrm{mL} \\
\text { (in vitro). }\end{array}$ & {$[30]$} \\
\hline V. tropica & $\begin{array}{l}\text { Mastoparan-VT7 } \\
\text { (INLKAIAALARNY) }\end{array}$ & Anti-E. faecalis at $5 \mu \mathrm{g} / \mathrm{mL}$ (in vitro). & {$[30]$} \\
\hline Polistes rothneyi iwatai & $\begin{array}{l}\text { Polistes-mastoparan-R1 } \\
(\text { Pm-R1) } \\
\left(\text { INWLKLGKKILGAI-NH }{ }_{2}\right)\end{array}$ & $\begin{array}{l}\text { Has histamine-releasing activities from rat mast cells } \\
\left(\mathrm{EC}_{50}=0.09 \mu \mathrm{M}\right) \text { (in vitro). }\end{array}$ & [80] \\
\hline P. rothneyi iwatai. & $\begin{array}{l}\text { Polistes-mastoparan-R3 } \\
\text { (Pm-R3) } \\
\left.\text { (INWLKLGKQILGAL-NH }{ }_{2}\right)\end{array}$ & $\begin{array}{l}\text { Has histamine-releasing activities from rat mast cells } \\
\left(\mathrm{EC}_{50}=0.19 \mathrm{mM}\right) \text { (in vitro). }\end{array}$ & [80] \\
\hline Vespa magnifica & Peptide 5e (FLPIIAKLLGLL) & Anti-S. aureus, MIC $=5 \mu \mathrm{g} / \mathrm{mL}$ (in vitro). & [83] \\
\hline V. magnifica & Peptide 5f (FLPIPRPILLGLL) & Anti-S. aureus, $\mathrm{MIC}=10 \mu \mathrm{g} / \mathrm{mL}$ (in vitro). & [83] \\
\hline V. magnifica & Peptide 5g (FLIIRRPIVLGLL) & Anti-S. aureus $\mathrm{MIC}=10 \mu \mathrm{g} / \mathrm{mL}$ (in vitro). & [83] \\
\hline V. magnifica & $\begin{array}{l}\text { Peptide 12a } \\
\text { (INWKGIAAMAKKLL) }\end{array}$ & $\begin{array}{l}\text { Anti-S. Aureus, and anti-C. albicans at } \\
\mathrm{MIC}=3.7 \mu \mathrm{g} / \mathrm{mL} \text { (in vitro). }\end{array}$ & [83] \\
\hline V. magnifica & $\begin{array}{l}\text { Peptide } 12 \mathrm{~b} \\
\text { (INWKGIAAMKKLL) }\end{array}$ & Anti-S. aureus MIC = $3.7 \mu \mathrm{g} / \mathrm{mL}$ (in vitro). & [83] \\
\hline P. dimorpha & $\begin{array}{l}\text { Polydim-I (AVAGEKL- } \\
\text { WLLPHLLKMLLTPTP) }\end{array}$ & $\begin{array}{l}\text { Antimycobacterial activity at } 7.6 \mu \mathrm{g} / \mathrm{mL} \text { (in vitro). } \\
\text { Anti-S. aureus at } \mathrm{MIC}_{50} 4.1 \mu \mathrm{g} / \mathrm{mL} \text { (in vitro). }\end{array}$ & {$[15,73]$} \\
\hline Anoplus samariensis & As-126 (EDPPVVKMK-NH ${ }_{2}$ ) & ND & {$[84]$} \\
\hline Batozonellus maculifrons & Bm-10 (ETAPVPKAISK-NH ${ }_{2}$ ) & ND & {$[84]$} \\
\hline A. samariensis & $\begin{array}{l}\text { Anoplin } \\
(\text { GLLKRIKTLL-NH })\end{array}$ & $\begin{array}{l}\text { Cytotoxic for T98G cells, gives 10\% inhibition at } \\
20 \mu \mathrm{mol} / \mathrm{L} \text { (in vitro). }\end{array}$ & {$[40,55]$} \\
\hline
\end{tabular}


Table 1. Cont

\begin{tabular}{|c|c|c|c|}
\hline Wasp-Scientific Name & Isolated Compounds & Biological Activity & Reference \\
\hline P. hypochondriaca & $\begin{array}{l}\text { Pimplin } \\
\text { (KRKPPRPNPKPKPIP) }\end{array}$ & $\begin{array}{l}\text { Effective against Musca domestica at dose of } 40 \mathrm{ng} \\
\text { (in vitro). }\end{array}$ & [85] \\
\hline $\begin{array}{l}\text { A. flavomarginatum } \\
\text { micado }\end{array}$ & $\begin{array}{l}\text { Af-113 } \\
\text { (INLLKIAKGIIKSLNH }{ }_{2} \text { ) }\end{array}$ & ND & [86] \\
\hline Agelaia vicina & $\begin{array}{l}\text { Agelaiatoxin-8 (AVTx8) } \\
\text { (INWKLGKALNALLNH } 2)\end{array}$ & $\begin{array}{l}\text { Inhibits gamma-aminobutyric acid (GABA) } \\
\text { neurotransmission uptake at } \mathrm{EC}_{50} \text { value of } \\
0.09 \pm 0.04 \mu \mathrm{M} \text { and maximum inhibition of } 97 \pm 5 \% \\
\text { (in vitro). }\end{array}$ & [87] \\
\hline Agelaia pallipes pallipes & $\begin{array}{l}\text { AgelaiaMP-I } \\
\text { (INWLKLGKAIIDAL-NH } 2 \text { ) }\end{array}$ & Has hemolytic activity at $\mathrm{ED}_{50}=60 \mu \mathrm{M}$. & [28] \\
\hline A. pallipes pallipes & $\begin{array}{l}\text { AgelaiaMP-II } \\
\text { (INWKAILQRIKKML-NH }\end{array}$ & Has hemolytic activity at $\mathrm{ED}_{50}=240 \mu \mathrm{M}$ (in vitro). & [88] \\
\hline $\begin{array}{l}\text { Anoplius samariensis, } \\
\text { and Batozonellus } \\
\text { maculifrons }\end{array}$ & $\begin{array}{l}\text { Pompilidotoxins ( } \alpha \text {-PMTXs) } \\
\text { (RIKIGLFDQLSKL-NH} 2)\end{array}$ & $\begin{array}{l}\text { Facilitates synaptic transfer in the motor neuron of } \\
\text { the lobster and delays downregulation of the } \\
\text { sodium channel (in vitro). }\end{array}$ & [89] \\
\hline $\begin{array}{l}\text { A. samariensis, and } B \text {. } \\
\text { maculifrons }\end{array}$ & $\begin{array}{l}\beta \text {-PMTXs } \\
(\text { RIKIGLFDQRSKL-NH } \\
\text { ) }\end{array}$ & $\begin{array}{l}\text { Facilitates synaptic transfer in the neuromuscular } \\
\text { junction of the lobster, and slows the sodium } \\
\text { channel inactivation (in vitro). }\end{array}$ & [89] \\
\hline $\begin{array}{l}\text { A. flavomarginatum } \\
\text { micado }\end{array}$ & $\begin{array}{l}\text { Eumenine mastoparan-AF } \\
\text { (EMP-AF) } \\
\left.\text { (INLLKIAKGIIKSL-NH }{ }_{2}\right)\end{array}$ & $\begin{array}{l}\text { Effective hemolytic response in human erythrocytes. } \\
\text { Enhancing degranulation of rat peritoneal mast cells } \\
\text { and RBL-2H3 cells (in vitro). }\end{array}$ & [81] \\
\hline $\begin{array}{l}\text { Agelaia pallipes pallipes, } \\
\text { and Protonectarina } \\
\text { sylveirae }\end{array}$ & $\begin{array}{l}\text { Protonectin } \\
\left(\text { ILGTILGLLKGL-NH }{ }_{2}\right)\end{array}$ & $\begin{array}{l}\text { Antibacterial activity towards Gram-positive and } \\
\text { Gram-negative bacteria. } \\
\text { Releasing Lactate dehydrogenase (LDH) from } \\
\text { mast cells. } \\
\text { Chemotaxis against polymorphonuclear leukocytes } \\
\text { (PMNL) (in vitro). }\end{array}$ & ([90] \\
\hline $\begin{array}{l}\text { A. pallipes pallipes, and } \\
\text { P. sylveirae }\end{array}$ & $\begin{array}{l}\text { Protonectin (1-6) } \\
\left.\text { (ILGTIL-NH }{ }_{2}\right)\end{array}$ & ND & [90] \\
\hline A. pallipes pallipes & $\begin{array}{l}\text { Protonectin (1-4)-OH } \\
\text { (ILGT-OH) }\end{array}$ & $\begin{array}{l}\text { Has poor hemolytic activity at } E_{50}=1 \mathrm{mM} \\
\text { (in vitro). }\end{array}$ & [88] \\
\hline A. pallipes pallipes & $\begin{array}{l}\text { Protonectin }(7-12) \\
(\text { GLLKGL-NH }\end{array}$ & ND & [88] \\
\hline A. pallipes pallipes & $\begin{array}{l}\text { Protonectin (1-5)-OH } \\
\text { (ILGTI-OH) }\end{array}$ & $\begin{array}{l}\text { Has weak hemolytic activity at } \mathrm{ED}_{50}=1 \mathrm{mM} \\
\text { (in vitro). }\end{array}$ & [88] \\
\hline A. pallipes pallipes & $\begin{array}{l}\text { Protonectin (1-6)-OH } \\
\text { (ILGTIL-OH) }\end{array}$ & $\begin{array}{l}\text { Has poor hemolytic activity at } \mathrm{ED}_{50}=1 \mathrm{mM} \\
\text { (in vitro). }\end{array}$ & [88] \\
\hline $\begin{array}{l}\text { Orancistrocerus } \\
\text { drewseni }\end{array}$ & $\begin{array}{l}\text { Orancis-protonectin } \\
\text { (ILGIITSLLKSL-NH }{ }_{2} \text { ) }\end{array}$ & $\begin{array}{l}\text { Has hemolytic activity of the sheep blood cells at } \\
50 \mu \mathrm{M} \text { (in vitro). }\end{array}$ & [91] \\
\hline A. pallipes pallipes & $\begin{array}{l}\text { Pallipine-I } \\
\text { (GIIDDQQCKKKPGQSSP } \\
\text { VCS-OH) }\end{array}$ & ND & [88] \\
\hline A. pallipes pallipes & $\begin{array}{l}\text { Pallipine-II } \\
\text { (SIKHKICKLLERTLKLTT } \\
\left.\text { PFC-NH }{ }_{2}\right)\end{array}$ & ND & [88] \\
\hline
\end{tabular}


Table 1. Cont

\begin{tabular}{|c|c|c|c|}
\hline Wasp-Scientific Name & Isolated Compounds & Biological Activity & Reference \\
\hline A. pallipes pallipes & $\begin{array}{l}\text { Pallipine-III } \\
\text { (SIKKHKCIALLERRGGS } \\
\text { KLPFC-NH }{ }_{2} \text { ) }\end{array}$ & ND & [88] \\
\hline P. paulista & $\begin{array}{l}\text { Paulistine (SIKDKICKIIQCGK } \\
\text { KLPFT-NH }{ }_{2} \text { ) } \\
\text { (oxidized form) }\end{array}$ & $\begin{array}{l}\text { Causes mast cells degranulation or hemolysis } \\
\text { (in vitro). }\end{array}$ & [92] \\
\hline Vespa mandarinia & $\begin{array}{l}\text { Ves-CP-M } \\
(\text { FLPILGKLLSGL-NH } \\
\text { ( ) }\end{array}$ & ND & [65] \\
\hline V. xanthoptera & Ves-CP-X (FLPIIAKLLGGLL) & ND & [65] \\
\hline Paravespula lewisi & Ves-CP-P (FLPIIAKLVSGLL) & ND & [65] \\
\hline V. tropica & Ves-CP-T (FLPILGKILGGLL) & ND & [65] \\
\hline V. crabro & $\begin{array}{l}\text { Crabrolin } \\
\text { (FLPLILRKIVTAL-NH2) }\end{array}$ & $\begin{array}{l}\text { Releases histamine from rat peritoneal mast cells at } \\
\mathrm{ED}_{50} \text { of } 11.8 \mu \mathrm{g} / \mathrm{mL} \text { (in vitro). }\end{array}$ & {$[93,94]$} \\
\hline Eumenes rubronotatus & $\begin{array}{l}\text { Eumenitin } \\
\text { (LNLKGIFKKVASLLT) }\end{array}$ & $\begin{array}{l}\text { Shows antimicrobial activity against S. aureus, } \\
\text { Staphylococcus saprophytius, E. coli at } \mathrm{MIC}=6 \mu \mathrm{M} \\
\text { (in vitro). }\end{array}$ & [95] \\
\hline E. rubrofemoratus & $\begin{array}{l}\text { Eumenine mastoparan-ER } \\
\text { (EMP-ER) } \\
\left(\text { FDIMGLIKKVAGAL-NH }{ }_{2}\right)\end{array}$ & $\begin{array}{l}\text { Anti-C. albicans at MIC } 7.5 \mu \mathrm{M} \text {. } \\
\text { Has Leishmanicidal activity at } \mathrm{IC}_{50} 20 \mu \mathrm{M} \text { (in vitro). }\end{array}$ & [96] \\
\hline Eumenes micado & $\begin{array}{l}\text { Eumenine mastoparan-EM1 } \\
\text { (LKLMGIVKKVLGAL-NH }{ }_{2} \text { ) }\end{array}$ & $\begin{array}{l}\text { Anti-S. aureus and anti-E. coli at MIC } 7 \mu \mathrm{M} \text { (in vitro). } \\
\text { Has Leishmanicidal activity with an } \mathrm{IC}_{50} \text { of } 36 \mu \mathrm{M} \\
\text { (in vitro). }\end{array}$ & [97] \\
\hline E. micado & $\begin{array}{l}\text { Eumenine mastoparan-EM2 } \\
\left(\text { LKLLGIVKKVLGAI-NH }{ }_{2}\right)\end{array}$ & $\begin{array}{l}\text { Anti-S. aureus and anti-E. coli at MIC of } 3 \mu \mathrm{M} \\
\text { (in vitro). } \\
\text { Has Leishmanicidal activity with an } \mathrm{IC}_{50} \text { of } 36 \mu \mathrm{M} \\
\text { (in vitro). }\end{array}$ & [97] \\
\hline Eumenes fraterculus & $\begin{array}{l}\text { Eumenine mastoparan-EF } \\
\text { (EMP-EF) } \\
\text { (FDVMGIIKKIASALNH }_{2}\end{array}$ & $\begin{array}{l}\text { Anti-C. albicans at MIC of } 7.5 \mu \mathrm{M} \text {. } \\
\text { Has Leishmanicidal behavior at } \mathrm{IC}_{50} \text { of } 40 \mu \mathrm{M} \\
\text { (in vitro). }\end{array}$ & [96] \\
\hline O. drewseni & $\begin{array}{l}\text { Eumenine mastoparan-OD } \\
\text { (EMP-OD) } \\
\left.\text { (GRILSFIKGLAEHL-NH }{ }_{2}\right)\end{array}$ & $\begin{array}{l}\text { Induces hemolysis of the sheep blood cells at } 50 \mu \mathrm{M} \\
\text { (in vitro). }\end{array}$ & [91] \\
\hline E. rubrofemoratus & $\begin{array}{l}\text { Eumenitin-R } \\
\text { (LNLKGLIKKVASLLN) }\end{array}$ & $\begin{array}{l}\text { Anti-Sreptococcus pyogenes, anti-Micrococcus luteus, } \\
\text { and anti-Stenotrophomonas maltophilia at } \\
\text { MIC of } 15 \mu \mathrm{M} \text {. } \\
\text { Anti-B. subtilis at MIC } 7.5 \mu \mathrm{M} \text { (in vitro). }\end{array}$ & [96] \\
\hline E. fraterculus & $\begin{array}{l}\text { Eumenitin-F } \\
\text { (LNLKGLFKKVASLLT) }\end{array}$ & $\begin{array}{l}\text { Anti-C. albicans at MIC of } 7.5 \mu \mathrm{M} \text {. } \\
\text { Has Leishmanicidal activity at } \mathrm{IC}_{50} \text { of } 52 \mu \mathrm{M} \\
\text { (in vitro). } \\
\text { Anti-S. maltophilia at MIC of } 15 \mu \mathrm{M} \text { (in vitro). }\end{array}$ & [96] \\
\hline P. paulista. & $\begin{array}{l}\text { Polybia-CP } \\
\left.\text { (ILGTILGLLKSL-NH }{ }_{2}\right)\end{array}$ & $\begin{array}{l}\text { Anti-microbial against S. aureus and B. subtilis at } 15 \\
\mu \mathrm{g} / \mathrm{mL} \text { compared with } 0.5 \text { and } 18 \mu \mathrm{g} / \mathrm{mL} \text { of } \\
\text { tetracycline (in vitro). }\end{array}$ & {$[14,65]$} \\
\hline \multirow[b]{2}{*}{ P. paulista } & $\begin{array}{l}\text { Polybia-CP } 2 \\
\text { (ILGTILGKIL-OH) }\end{array}$ & $\begin{array}{l}\text { Has chemotaxis, mast cell degranulation, and } \\
\text { hemolytic activities (in vivo). }\end{array}$ & [98] \\
\hline & $\begin{array}{l}\text { Polybia-CP } 3 \\
\left.\text { (ILGTILGTFKSL-NH }{ }_{2}\right)\end{array}$ & $\begin{array}{l}\text { Has chemotaxis, mast cell degranulation, and } \\
\text { hemolytic activities (in vivo). } \\
\text { Antiplasmodial and anticancer properties (in vitro). }\end{array}$ & {$[8,98]$} \\
\hline
\end{tabular}


Table 1. Cont

\begin{tabular}{|c|c|c|c|}
\hline Wasp-Scientific Name & Isolated Compounds & Biological Activity & Reference \\
\hline P. paulista & $\begin{array}{l}\text { Polybia-MP1 } \\
\text { (IDWKKLLDAAKQIL-NH }{ }_{2} \text { ) }\end{array}$ & $\begin{array}{l}\text { Antitumor against bladder and prostate cancer cells. } \\
\text { Exhibits potent activity against } S \text {. aureus, MIC of } \\
9 \mu \mathrm{M} \text { (in vitro). } \\
\text { Anti-C. albicans }\left(\mathrm{EC}_{50}=12.9 \mu \mathrm{M}\right) \text { and } C \text {. neoformans } \\
\left(\mathrm{EC}_{50}=11 \mu \mathrm{M}\right) \text { (in vitro). } \\
\text { Fungicidal activity against Candida glabrata } \\
\left(\mathrm{EC}_{50}=8 \mu \mathrm{M}\right) \text { and C. albicans }\left(\mathrm{EC}_{50}=16 \mu \mathrm{M}\right) \\
\text { (in vitro). } \\
\text { Anti-E. coli, P. aeruginosa, B. subtilis, and S. aureus at } \\
\text { MIC of } 8,8,4 \text {, and } 15 \mu \mathrm{g} / \mathrm{mL} \text { compared to } 2,18,18 \text {, } \\
\text { and } 0.5 \text { of tetracycline (in vitro). }\end{array}$ & {$[64,85]$} \\
\hline V. orientalis L. & $\begin{array}{l}\text { HR-1 } \\
\text { (INLKAIAALVKKVL-NH }\end{array}$ & ND & [99] \\
\hline V. orientalis L. & $\begin{array}{l}\text { HR-2 } \\
\left(\text { FLPLILGKLVKGLL-NH }{ }_{2}\right)\end{array}$ & ND & [99] \\
\hline Polistes jadwigae & $\begin{array}{l}\text { Polisteskinin-J } \\
\text { (RRRPPGFSPFR-OH) }\end{array}$ & ND & [98] \\
\hline Pollistes chiensis & $\begin{array}{l}\text { Polisteskinin-C } \\
\text { (SKRPPGFSPFR-OH) }\end{array}$ & ND & [98] \\
\hline P. rothney & $\begin{array}{l}\text { Polisteskinin-R } \\
\text { (ARRPPGFTPFR-OH) }\end{array}$ & $\begin{array}{l}\text { Exerts potent anxiolytic effects at } 6,3 \text {, and } 1.5 \text { ๆmol } \\
\text { compared to positive control Diazepam (in vivo) }\end{array}$ & {$[98,100]$} \\
\hline Vespa analis & $\begin{array}{l}\text { Vespakinin-A } \\
\text { (GRPPGFSPFRVI-OH) }\end{array}$ & ND & [98] \\
\hline Vespa mandarínia & $\begin{array}{l}\text { Vespakinin-X } \\
\text { (ARPPGFSPFR-OH) }\end{array}$ & ND & [98] \\
\hline $\begin{array}{l}\text { V. magnifica, } \\
\text { Parapolybia varia, } \\
\text { V. tropica }\end{array}$ & $\begin{array}{l}\text { Vespid Chemotactic } \\
\text { Peptides (VCP) }\end{array}$ & $\begin{array}{l}\text { Anti-tumor activities towards NIH-OVCAR-3 and } \\
\text { SK-OV-3 ovarian cancer cell lines at concentrations } \\
\text { higher than } 10 \mu \mathrm{M} \text { (in vitro). }\end{array}$ & {$[34,101]$} \\
\hline V. magnifica (Smith) & $\begin{array}{l}\text { VCP-5h } \\
\text { (FLPIIGKLLSGLL-NH } 2 \text { ) }\end{array}$ & $\begin{array}{l}\text { MICs of } 5,25 \text {, and } 30, \mu \mathrm{g} / \mathrm{mL} \text { for } S \text {. aureus, } \\
\text { C. albicans and E. coli, respectively (in vitro). }\end{array}$ & [102] \\
\hline Parapolybia varia & Vespakinin (Vespk) & $\begin{array}{l}\text { Antitumor activity to SK-OV-3 at } 24 \mathrm{~h} \\
\text { post-treatment (in vitro). }\end{array}$ & [101] \\
\hline V. magnifica & $\begin{array}{l}\text { Vespakinin-M } \\
\text { GRPPGFSPFRID }\end{array}$ & ND & [103] \\
\hline Batozonellus maculifrons & $\begin{array}{l}\text { Pompilidotoxins }\left(\beta-{ }^{-P M T X s}\right) \\
\left.\text { (RIKIGLFDQLSRL-NH}{ }_{2}\right)\end{array}$ & $\begin{array}{l}\text { Inactivation of the } \mathrm{Na}^{+} \text {channel, and the Nav1.6 } \\
\text { channel was more selective (in vitro). }\end{array}$ & [1] \\
\hline O. drewseni & $\begin{array}{l}\text { OdVP1 } \\
(\text { GRILSFIKGLAEHL-NH }\end{array}$ & $\begin{array}{l}\text { Anti-E. coli, and anti-C. albicans at MIC of } 6 \mu \mathrm{M} \\
\text { (in vitro). }\end{array}$ & {$[104,105]$} \\
\hline O. drewseni & OdVP2 (ILGIITSLLKSL-NH ${ }_{2}$ ) & $\begin{array}{l}\text { Anti-S. aureus at MIC of } 25 \mu \mathrm{g} / \mathrm{mL} \text {. } \\
\text { Anti-gray mold Botrytis cinerea at MIC of } 0.4 \mu \mathrm{M} \\
\text { (in vitro). }\end{array}$ & {$[104,105]$} \\
\hline O. drewseni & $\begin{array}{l}\text { OdVP3 } \\
\text { (KDLHTVVSAILQAL-NH }{ }_{2} \text { ) }\end{array}$ & Anti-gray mold B. cinerea at MIC of $5 \mu \mathrm{M}$ (in vitro). & {$[104,105]$} \\
\hline O. drewseni & $\begin{array}{l}\text { OdVP4 } \\
\text { (LDPKVVQSLL-NH }{ }_{2} \text { ) }\end{array}$ & ND & [104] \\
\hline
\end{tabular}


Table 1. Cont.

\begin{tabular}{|c|c|c|c|}
\hline Wasp-Scientific Name & Isolated Compounds & Biological Activity & Reference \\
\hline Nasonia vitripennis & $\begin{array}{l}\text { Defensin-NV (VTCELLMFG- } \\
\text { GVVGDSACAANCLSMGK- } \\
\text { AGGSCNGGLCDCRKT- } \\
\text { TFKELWDKRFG) }\end{array}$ & $\begin{array}{l}\text { Anti-S. aureus, and Anti-B. cereus at MIC of } 0.93 \mu \mathrm{M} \\
\text { (in vitro). } \\
\text { Anti-B. dysenteriae at MIC of } 0.46 \mu \mathrm{M} \text { (in vitro). } \\
\text { Anti-E. coli, and anti-C. albicans at MIC of } 1.86 \mu \mathrm{M} \\
\text { (in vitro). } \\
\text { Anti-P. aeruginosa at MIC of } 9.3 \mu \mathrm{M} \text { (in vitro). }\end{array}$ & [106] \\
\hline Chartergellus communis & $\begin{array}{l}\text { Communis } \\
\text { (INWKAILGKIGK-COOH) }\end{array}$ & ND & [107] \\
\hline C. communis & $\begin{array}{l}\text { Communis-AAAA } \\
\left(\text { INWKAILGKIGKAAAAVNH }_{2}\right)\end{array}$ & $\begin{array}{l}\text { Hemolytic activity at } \mathrm{EC}_{50}=142.6 \mu \mathrm{M} \text { (in vitro). } \\
\text { Hyperalgesic effect at } 2 \mathrm{nmol} / \text { animal (in vivo). }\end{array}$ & [107] \\
\hline $\begin{array}{l}\text { Cyphononyx } \\
\text { Fulvognathus }\end{array}$ & $\begin{array}{l}\text { Bradykinin } \\
\text { (RPPGFSPFR) }\end{array}$ & $\begin{array}{l}\text { Acts as a chemoattractant directing glioma cells into } \\
\text { blood vessels in the brain of rats (in vivo). }\end{array}$ & [108] \\
\hline $\begin{array}{l}\text { Megascolia flavifrons, } \\
\text { and Colpa interrupta }\end{array}$ & $\begin{array}{l}\text { Megascoliakinin = } \\
\text { Thr6BK-Lys-Ala (BK = } \\
\text { bradykinin) (RPPGFTPFRKA) }\end{array}$ & $\begin{array}{l}\text { Prevents the synaptic transmission of the nicotinic } \\
\text { acetylcholine receptor ( } \mathrm{nAChR} \text { ) in the central } \\
\text { nervous system of insect (in vitro). }\end{array}$ & [109] \\
\hline $\begin{array}{l}\text { C. fulvognathus } \\
\text { and P. paulista }\end{array}$ & $\begin{array}{l}\text { RA-Thr6 -Bradykinin } \\
\text { (RARPPGFTPFR-OH) }\end{array}$ & ND & [98] \\
\hline $\begin{array}{l}\text { Polybia occidentalis, } M . \\
\text { flavifrons, C. interrupta, } \\
\text { and P. paulista }\end{array}$ & $\begin{array}{l}\text { Threonine6-bradykinin } \\
\text { (Thr6-BK) } \\
\text { RPPGFTPFR-OH }\end{array}$ & $\begin{array}{l}\text { Anti-nociceptive effects with approximately } \\
\text { two-fold higher than bradykinin and morphine } \\
\text { (in vivo). }\end{array}$ & {$[98,110]$} \\
\hline P. paulista & $\begin{array}{l}\text { RA-Thr6 -Bradykinin-DT } \\
\text { (RARPPGFTPFRDT-OH) }\end{array}$ & ND & [98] \\
\hline C. fulvognathus & $\begin{array}{l}\text { Fulvonin } \\
\text { (SIVLRGKAPFR) }\end{array}$ & $\begin{array}{l}\text { Displays hyperalgesic impact after intraplantar } \\
\text { injection in the rat paw pressure test (in vivo). }\end{array}$ & [111] \\
\hline $\begin{array}{l}\text { C. fulvognathus } \\
\text { (Japan) }\end{array}$ & Cyphokinin (DTRPPGFTPFR) & $\begin{array}{l}\text { Demonstrates hyperalgesic impact after intraplantar } \\
\text { injection in the rat paw pressure test (in vivo). }\end{array}$ & [111] \\
\hline $\begin{array}{l}\text { C. fulvognathus } \\
\text { (Japan) }\end{array}$ & $\begin{array}{l}\text { Cd-146 } \\
\text { (SETGNTVTVKGFSPLR) }\end{array}$ & $\begin{array}{l}\text { Shows hyperalgesic effect in the rat paw pressure } \\
\text { test after intraplantar injection (in vivo). }\end{array}$ & [111] \\
\hline C. fulvognathus & Cd-125 (DTARLKWH) & ND & [111] \\
\hline P. paulista & $\begin{array}{l}\text { Mastoparan (MPI) } \\
\text { (IDWKKLLDAAKQIL-NH } 2 \text { ) }\end{array}$ & $\begin{array}{l}\text { Cytotoxic towards T98G cells, gives 30\% inhibition } \\
\text { at } 20 \mu \mathrm{mol} / \mathrm{L} \text { (in vitro). }\end{array}$ & {$[40]$} \\
\hline
\end{tabular}

Anti-staphylococcal activity with an $\mathrm{EC}_{50}$ of $1.83 \mu \mathrm{M}$ and $\mathrm{EC}_{90}$ of $2.90 \mu \mathrm{M}$ (in vitro).

Mice treated with $5 \mathrm{mg} / \mathrm{kg}$ showed a decline in bacterial load from 108 to ca. 106 CFUs (in vitro). Potent hemolytic activity against mouse cells $\left(\mathrm{EC}_{50}=24.18 \mathrm{Mm}, \mathrm{EC}_{90}=58.12 \mu \mathrm{M}\right)$ (in vitro).

Pseudopolybia vespiceps Mastoparan Polybia-MPII (INWLKLGKMVIDAL-NH${ }_{2}$ )
Inhibits the growth of $C$. neoformans $\left(\mathrm{EC}_{50}=11 \mu \mathrm{M}\right)$

and C. albicans $\left(\mathrm{EC}_{50}=12.9 \mu \mathrm{M}\right)$ (in vitro).

Anti-A. baumannii AB 0 at MIC of $12.5 \mu \mathrm{M}$ while MIC against $A$. baumannii $\mathrm{AB} 53$ and $\mathrm{AB} 72$ was $6.25 \mu \mathrm{M}$ (in vitro).

Adhesion inhibition for A. baumannii $\mathrm{AB} 02$ and $\mathrm{AB}$ 72 at $25 \mu \mathrm{M}$ while $A$. baumannii $\mathrm{AB} 53$ was inhibited at a concentration of $12.5 \mu \mathrm{M}$ (in vitro).

\begin{tabular}{ll}
\hline P. paulista & $\begin{array}{l}\text { Polybia-MPIII } \\
\text { (INWLKLGKAVIDAL) }\end{array}$ \\
\hline P. paulista & $\begin{array}{l}\text { Polybia-MP IV } \\
\text { (IDWLKLRVISVIDL-NH }\end{array}$ )
\end{tabular}

Anti-S. aureus, MIC of $19 \mu \mathrm{M}$ (in vitro).

Shows strong mast cell degranulation.

Has weak haemolytic activity, hypernociception and edema formation (in vitro).

\section{[98]}


Table 1. Cont

\begin{tabular}{|c|c|c|c|}
\hline Wasp-Scientific Name & Isolated Compounds & Biological Activity & Reference \\
\hline P. paulista & $\begin{array}{l}\text { Polybia-MP V } \\
\text { (INWHDIAIKNIDAL-NH } 2 \text { ) }\end{array}$ & $\begin{array}{l}\text { Medium mast cell degranulation, haemolytic activity } \\
\text { and hypernociception (in vitro). }\end{array}$ & [98] \\
\hline P. paulista & $\begin{array}{l}\text { Polybia-MP VI } \\
\text { (IDWLKLGKMVM-OH) }\end{array}$ & $\begin{array}{l}\text { Medium haemolytic activity and hypernociception } \\
\text { (in vitro). }\end{array}$ & [98] \\
\hline P. paulista & unk-1 (IPAGWAIVKV-NH ${ }_{2}$ ) & $\begin{array}{l}\text { Shows weak mast cell degranulation and haemolytic } \\
\text { activity (in vitro). }\end{array}$ & [98] \\
\hline P. paulista & unk-2 (TGDSPDVR-OH) & $\begin{array}{l}\text { Shows weak mast cell degranulation and haemolytic } \\
\text { activity, weak chemotaxis for PMNLs, and a range of } \\
\text { weak to strong hypernociception and oedema } \\
\text { formation (in vitro). }\end{array}$ & [98] \\
\hline$V$. orientalis $L$. & $\begin{array}{l}\text { Orientotoxin } \\
\text { (Neurotoxin) }\end{array}$ & $\begin{array}{l}\text { Has lysophospholipase activity and inhibits both } \\
\text { mediated and spontaneous release of the } \\
\text { neurotransmitter from the presynaptic nerve } \\
\text { membrane (in vivo). }\end{array}$ & {$[113,114]$} \\
\hline V. orientalis L. & Peptide I (AGVILFGR-NH ${ }_{2}$ ) & $\begin{array}{l}\text { Histamine release from mast cells } \mathrm{ED}_{50}=5 \cdot 10^{-7} \\
\text { (in vivo). }\end{array}$ & [115] \\
\hline V. orientalis L. & Peptide II (AGVIFRSP-NH ${ }_{2}$ ) & $\begin{array}{l}\text { Histamine release from mast cells } \mathrm{ED}_{50}=3 \cdot 10^{-6} \\
\text { (in vivo). }\end{array}$ & [115] \\
\hline $\begin{array}{l}\text { Oreumenes } \\
\text { decoratus }\end{array}$ & $\begin{array}{l}\text { Decoralin }\left(\mathrm{De}-\mathrm{NH}_{2}\right) \\
(\text { SLLSLIRKLIT-NH} \\
2\end{array}$ & $\begin{array}{l}\text { Has hemolytic activity at } \mathrm{EC}_{50} \text { of } 80 \mu \mathrm{M} \text { (in vitro). } \\
\text { Anti-S. aureus, } \mathrm{MIC}=4 \mu \mathrm{M} \text { (in vitro). } \\
\text { Anti-B. Subtilis, } \mathrm{MIC}=8 \mu \mathrm{M} \text { (in vitro). } \\
\text { Anti-C. albicans, MIC }=20 \mu \mathrm{M} \text { (in vitro). } \\
\text { Has leishmanicidal activity, } \mathrm{IC}_{50}=11 \mu \mathrm{M} \text { (in vitro). }\end{array}$ & {$[61]$} \\
\hline V. ducalis & $\begin{array}{l}\text { VACP1 } \\
\text { (AQKWLKYWKADKVKG } \\
\text { FGRKIKKIWFG) }\end{array}$ & $\begin{array}{l}\text { Potently inhibits cell proliferation and promotes the } \\
\text { cell apoptosis of osteosarcoma (OS) cells, and this } \\
\text { was concomitant with the activation of the JNK and } \\
\text { p38 MAPK signaling pathway (in vitro). }\end{array}$ & {$[6]$} \\
\hline \multirow{3}{*}{$\begin{array}{l}\text { Emerald Jewel, and } \\
\text { Ampulex compressa }\end{array}$} & $\begin{array}{l}\text { Ampulexin-1 (axn1) } \\
\text { (CKDDYVNPKEQLGY- } \\
\text { DILEKLRQKP) }\end{array}$ & ND & [116] \\
\hline & $\begin{array}{l}\text { Ampulexin -2 (axn2) } \\
\text { (CQNDYVNPKLQFACDL- } \\
\text { LQKAKERQ) }\end{array}$ & ND & [116] \\
\hline & $\begin{array}{l}\text { Ampulexin }-3 \text { axn3 } \\
\text { SFSMLLQKAKERQ }\end{array}$ & ND & [116] \\
\hline$V$. orientalis & $\begin{array}{l}\text { AuNPs+ peptide } \\
\text { (INLKAIAALVKKV) }\end{array}$ & $\begin{array}{l}\text { Antibacterial using AuNPs against K. pneumoniae, } \\
\text { B. cereus, S. mutans, S. typhimuriu, E. coli, and } \\
\text { S. aureus, and with the inhibition zones of 9.21, 14.32, } \\
\text { 14.71,19.21, } 15.24 \text { and } 15.33 \mathrm{~mm} \text {, respectively } \\
\text { (in vitro). }\end{array}$ & [19] \\
\hline Vespa bicolor Fabricius & $\begin{array}{l}V . \text { chemotatic peptide } \\
\text { (VESP-VBs) } \\
\text { (FMPIIGRLMSGSL) }\end{array}$ & Anti-S. aureus, MIC $=1 \mu \mathrm{g} / \mathrm{mL}$ (in vitro). & [5] \\
\hline V. bicolor Fabricius & $\begin{array}{l}\text { V. mastoparan (MP-VBs) } \\
\text { (INMKASAAVAKKLL) }\end{array}$ & Anti-S. aureus, $\mathrm{MIC}=1.9 \mu \mathrm{g} / \mathrm{mL}$ (in vitro). & [5] \\
\hline Polistes dominulus & $\begin{array}{l}\text { Dominulin A } \\
\text { (INWKKIAEVGGKILSSL) }\end{array}$ & $\begin{array}{l}\text { Anti-B. Subtilis, and E. coli at MIC }=2 \text { and } 8 \mu \mathrm{g} / \mathrm{mL} \text {, } \\
\text { respectively (in vitro). }\end{array}$ & [117] \\
\hline
\end{tabular}


Table 1. Cont

\begin{tabular}{|c|c|c|c|}
\hline Wasp-Scientific Name & Isolated Compounds & Biological Activity & Reference \\
\hline P. dominulus & $\begin{array}{l}\text { Dominulin B } \\
\text { (INWKKIAEIGKQVLSAL) }\end{array}$ & $\begin{array}{l}\text { Anti-B. Subtilis, and } E \text {. coli at MIC }=2 \text { and } 8 \mu \mathrm{g} / \mathrm{mL} \text {, } \\
\text { respectively (in vitro). }\end{array}$ & [17] \\
\hline Protonectarina sylveirae & $\begin{array}{l}\text { Protonectarina-MP } \\
\text { (INWKALLDAAKKVL) }\end{array}$ & $\begin{array}{l}\text { Anti-B. subtilis and anti-S. Aureus MIC }=3.9 \mu \mathrm{g} / \mathrm{mL} \\
\text { (in vitro). }\end{array}$ & [69] \\
\hline Parapolybia indica & $\begin{array}{l}\text { Parapolybia-MP } \\
(\text { INWKKMAATALKMI-NH} 2)\end{array}$ & Anti-S. aureus, $\mathrm{MIC}=3.9 \mu \mathrm{g} / \mathrm{mL}$ (in vitro). & [69] \\
\hline P. jadwigae & $\begin{array}{l}\text { Polistes mastoparan } \\
\text { (VDWKKIGQHIKSVL) }\end{array}$ & Degranulation of mast cells at $5 \mathrm{nM} / \mathrm{mL}$. & [39] \\
\hline V. magnifica (Smith) & $\begin{array}{l}\text { Vespid chemotactic peptide } \\
\text { (VCP) }\end{array}$ & $\begin{array}{l}\text { MICs for S. aureus, C. albicans, and E. coli were } 5,25 \text {, } \\
\text { and } 30, \mu \mathrm{g} / \mathrm{mL} \text {, respectively (in vitro). }\end{array}$ & [102] \\
\hline V. bicolor Fabricius & $\begin{array}{l}\text { VESP-VB1 } \\
\text { (FMPIIGRLMSGSL) }\end{array}$ & $\begin{array}{l}\text { Anti- } E \text {. coli, } \mathrm{MIC}=7.5 \mu \mathrm{g} / \mathrm{mL} \text { (in vitro). } \\
\text { Anti-S. aureus, } \mathrm{MIC}=1.9 \mu \mathrm{g} / \mathrm{mL} \text { (in vitro). } \\
\text { Anti- } P \text {. aeruginosa, } \mathrm{MIC}=3.75 \mu \mathrm{g} / \mathrm{mL} \text { (in vitro). } \\
\text { Anti-C. albicans, } \mathrm{MIC}=30 \mu \mathrm{g} / \mathrm{mL} \text { (in vitro). }\end{array}$ & {$[5]$} \\
\hline V. bicolor Fabricius & $\begin{array}{l}\text { MP-VB1 } \\
\text { (INMKASAAVAKKLL) }\end{array}$ & $\begin{array}{l}\text { Anti-E. coli, } \mathrm{MIC}=15 \mu \mathrm{g} / \mathrm{mL} \text { (in vitro). } \\
\text { Anti-S. aureus, } \mathrm{MIC}=3.75 \mu \mathrm{g} / \mathrm{mL} \text { (in vitro). } \\
\text { Anti-P. aeruginosa, } \mathrm{MIC}=15 \mu \mathrm{g} / \mathrm{mL} \text { (in vitro). } \\
\text { Anti-C. albicans, MIC }=15 \mu \mathrm{g} / \mathrm{mL} \text { (in vitro). }\end{array}$ & [5] \\
\hline V. tropica & VCP-VT1 & $\begin{array}{l}\text { Anti-E. coli, Enterobacter cloacae, and C. parapsilosis at } \\
2.5 \mu \mathrm{g} / \mathrm{mL} \text { and Anti-S. aureus at } 1.2 \mu \mathrm{g} / \mathrm{mL} \\
\text { (in vitro). }\end{array}$ & {$[30]$} \\
\hline V. tropica & $\begin{array}{l}\text { VCP-VT2 } \\
\text { FLPIIGKLLSG }\end{array}$ & $\begin{array}{l}\text { Antimicrobial against } S \text {. aureus, E. cloacae at } 2.5 \\
\mu \mathrm{g} / \mathrm{mL} \text { (in vitro). }\end{array}$ & {$[30]$} \\
\hline $\begin{array}{l}\text { Protopolybia exigua } \\
\text { (Kinins) }\end{array}$ & $\begin{array}{l}\text { Protopolybiakinin-I } \\
\text { (DKNKKPIRVGGRRP } \\
\text { PGFTR-OH) }\end{array}$ & $\begin{array}{l}\text { Caused degranulation of } 35 \% \text { of the mast cells } \\
\text { (in vitro). }\end{array}$ & [118] \\
\hline P. exigua & $\begin{array}{l}\text { Protopolybiakinin-II (Kinins) } \\
\text { (DKNKKPIWMAGFPG } \\
\text { FTPIR-OH) }\end{array}$ & $\begin{array}{l}\text { Caused degranulation of } 52 \% \text { of the mast cells } \\
\text { (in vitro). }\end{array}$ & [118] \\
\hline V. mandarinia & $\begin{array}{l}\text { VESCP-M2 } \\
\text { (FLPILAKILGGLL) }\end{array}$ & $\begin{array}{l}\text { Induces pain and severe tissue injury, oedema, } \\
\text { cutaneous necrosis, and blister. }\end{array}$ & [119] \\
\hline Polistes lanio lanio & $\begin{array}{l}\text { PllTkP-I } \\
\text { (QPPTPPEHRFPGLM) }\end{array}$ & ND & [120] \\
\hline P. lanio lanio & $\begin{array}{l}\text { PllTkP-II } \\
\text { (ASEPTALGLPRIFPGLM) }\end{array}$ & ND & [120] \\
\hline V. magnifica (Smith) & 5-Hydroxytryptamine & $\mathrm{ND}$ & [121] \\
\hline V. magnifica (Smith) & $\begin{array}{l}\text { Vespakinin-M } \\
\left(\text { GRPPGFSPFRID-NH }{ }_{2}\right)\end{array}$ & ND & [121] \\
\hline V. magnifica (Smith) & $\begin{array}{l}\text { Mastoparan M } \\
\left(\text { INLKAIAALAKKLL-NH }{ }_{2}\right)\end{array}$ & ND & [121] \\
\hline V. magnifica (Smith) & $\begin{array}{l}\text { Vespid chemotactic peptide M } \\
\left(\text { FLPIIGKLLSGLL-NH }{ }_{2}\right)\end{array}$ & ND & [121] \\
\hline $\begin{array}{l}\text { Sphex argentatus } \\
\text { argentatus }\end{array}$ & Sa12b (EDVDHVFLRF) & $\begin{array}{l}\text { Inhibits acid-sensing ion channels (ASIC) of rat } \\
\text { dorsal root ganglion (DRG) neurons at } \mathrm{IC}_{50} \text { of } 81 \mathrm{nM} \\
\text { while inhibiting it completely at } 1 \mu \mathrm{M} \text { (in vivo). }\end{array}$ & [122] \\
\hline Isodontia harmandi & Sh5b(DVDHVFLRF-NH ${ }_{2}$ ) & ND & [122] \\
\hline P. paulista & Neuropolybin & Antiseizure & [37] \\
\hline
\end{tabular}


Table 1. Cont

\begin{tabular}{|c|c|c|c|}
\hline Wasp-Scientific Name & Isolated Compounds & Biological Activity & Reference \\
\hline Synoeca surinama & $\begin{array}{l}\text { Synoeca-MP } \\
\text { I/LNWI/LKI/LGKKI/LI/ } \\
\text { LASL/ } \mathrm{NH}_{2}\end{array}$ & $\begin{array}{l}\text { Antimicrobial activity, } \mathrm{MIC}_{50} \text { values were } 1.9,2,8.3 \text {, } \\
\text { 5.2, and } 3.5 \mu \mathrm{M} \text { for methicillin-resistant } \\
\text { S. aureus-MRSA, E. coli ESBL, vancomycin-resistant } \\
\text { E. Faecalis, P. aeruginosa metallo-ß-lactamase, and } \\
\text { Klebsiella pneumoniae KPC, respectively (in vitro). } \\
\text { Anti-Candida species, with MICs varying from } \\
10-40 \mu \mathrm{M} \text { (in vitro). }\end{array}$ & [123] \\
\hline \multicolumn{4}{|l|}{ Enzymes and proteins } \\
\hline V. magnifica & Magnifin (PLA1) & $\begin{array}{l}\text { Activates platelet aggregation and induces } \\
\text { thrombosis at } 18 \mathrm{nM} \text { with causes } 85 \% \text { washed } \\
\text { platelets aggregation in } 60 \mathrm{~s} \text { (in vivo). }\end{array}$ & [124] \\
\hline $\begin{array}{l}\text { P. paulista } \\
\text { (southeast Brazil) }\end{array}$ & Phospholipase A1(Ves v 1) & $\begin{array}{l}\text { Catalyzes the ester bonds hydrolysis of 1,2-diacyl-3 } \\
\text { snglycerophospholipids at the sn-1 and sn-2 } \\
\text { positions, respectively. }\end{array}$ & [125] \\
\hline P.paulista & Phospholipase $\mathrm{A}_{1}$ & $\begin{array}{l}\text { Hydrolyzes phospholipids and produces } \\
\text { 2-acyl-lysophospholipids and fatty acids. }\end{array}$ & {$[125,126]$} \\
\hline $\begin{array}{l}\text { P. Occidentalis and } P . \\
\text { paulista }\end{array}$ & Phospholipase A2 (PLA2) & $\begin{array}{l}\text { Potent hemolytic actions in washed red cells } \\
\text { (in vitro). } \\
\text { Hydrolyzes natural phospholipids, catalysing the } \\
\text { deacylation of 1,2-diacyl-sn-3-phosphoglycerides at } \\
\text { position } 2 \text { and thus releases free fatty acids and } \\
\text { lysophospholipids (in vitro). }\end{array}$ & {$[127,128]$} \\
\hline
\end{tabular}

\begin{tabular}{|c|c|c|c|}
\hline $\begin{array}{l}\text { P. paulista, Vespula } \\
\text { maculate, Vespula } \\
\text { arenaria, V. crabro, } \\
\text { V. orientalis, } \\
\text { Paravespula germanica, } \\
\text { Paravespula vulgaris, } \\
\text { Dolichovespula saxonica, } \\
\text { Dolichovespula media, } \\
\text { and Polistes Gallicus }\end{array}$ & Hyaluronidase (Polyp2) & $\begin{array}{l}\text { Hydrolyses hyaluronic acid which facilitates the } \\
\text { diffusion of toxin into the tissue and blood } \\
\text { circulation of the prey. }\end{array}$ & [129-131] \\
\hline Polistes comanchus & Polistin (protein) & $\begin{array}{l}\text { Responsible for the cytotoxic effect of the } \\
\text { whole venom. }\end{array}$ & [132] \\
\hline P. paulista & Antigen5 (Polyp5) & $\begin{array}{l}\text { Major allergen could be used for allergy diagnostics } \\
\text { and treatment. }\end{array}$ & [133] \\
\hline Cyphononyx dorsalis & Arginine kinase-like protein & $\begin{array}{l}\text { Exhibits paralytic activity in spiders with the same } \\
\text { characteristic symptoms as the crude venom. }\end{array}$ & [134] \\
\hline Pteromalus puparum & $\begin{array}{l}\text { Vn.11 } \\
\text { (protein) }\end{array}$ & ND & [135] \\
\hline Cotesia rubecula & Vn 4.6 & ND & [136] \\
\hline V. magnifica & Magnvesin & $\begin{array}{l}\text { Exerts anti-coagulant properties via hydrolyzing } \\
\text { coagulant factors VII, VIII, TF, IX and X. }\end{array}$ & [137] \\
\hline \multicolumn{4}{|l|}{ Some volatile compounds } \\
\hline Vespa velutina & Undecan-2-one & \multirow{5}{*}{ Elicits the defense behavior } & \multirow{5}{*}{ [138] } \\
\hline V. velutina & Non-8-en-2-one & & \\
\hline V. velutina & Nonan-2-one & & \\
\hline$V$. velutina & Heptan-2-one & & \\
\hline$V$. velutina & 4,8-Dimethylnon-7-en-2-one & & \\
\hline
\end{tabular}


Table 1. Cont.

\begin{tabular}{|c|c|c|c|}
\hline Wasp-Scientific Name & Isolated Compounds & Biological Activity & Reference \\
\hline $\begin{array}{l}\text { Polistes metricus Say, } \\
\text { Polistes bellicosus } \\
\text { Cresson, and Polistes } \\
\text { dorsalis (F.), as well as } \\
\text { workers of Polistes } \\
\text { aurifer (Saussure), } \\
\text { P. bellicosus, P. metricus, } \\
\text { and P. dorsalis }\end{array}$ & N-(3-Methylbutyl)acetamide & ND & [139] \\
\hline P. occidentalis & $\begin{array}{l}\text { (E,E)-2,8-Dimethyl1,7- } \\
\text { dioxaspiro[5.5]undecane }\end{array}$ & Elicit the defense behavior & [140] \\
\hline
\end{tabular}

ND: Not detected

\section{Application of Wasp Venom and Their Nests in Nanotechnology}

There is an increasing awareness of the use of metabolites of arthropods including insect for the green synthesis of nanoparticles [141]. In this context, Jalaei and colleagues published the first study on the green synthesis of gold nanoparticles (AuNPs) using $V$. orientalis wasp venom peptides. The AuNPs had been fabricated by adding $25 \mathrm{~mL}$ of stabilized SDS-NPs suspension (AuNP and SDS surfactant) to $750 \mu \mathrm{L}$ of purified peptides $(20 \mu \mathrm{M})$. The crystalline gold nanoparticles have been characterized ((TEM; average size $23.2 \pm 2.7 \mathrm{~nm}$ ), (XRD; average size $35 \mathrm{~nm}$ ), (UV where the peak of AuNPs confirmed at $555 \mathrm{~nm})$ ), and FTIR data demonstrated that amide, amine, peptide, and protein compounds were involved in AuNP biosynthesis. Furthermore, wasp venom-mediated AuNPs depicted good antibacterial activity using microdilution assay against E. coli, K. pneumonia, S. typhimurium, S. aureus, S. mutans, and B. cereus with MIC values of 5.11, 10.08, 11.66, 28.04, 18.78 , and $28.12 \mu \mathrm{g} / \mathrm{mL}$, respectively, in comparison with the positive control (tetracycline, MIC $=0.98-2.21 \mu \mathrm{g} / \mathrm{mL}$ ) and peptides (MIC $=11.77-59.66 \mu \mathrm{g} / \mathrm{mL})$ [19].

Not only can wasp venom be utilized for the green synthesis of nanoparticles, but wasp nests can also be used for this application. In this context, Lateef and colleagues utilized paper wasp (Polistes sp.) nests to biofabricate silver nanoparticles by interacting $1 \mathrm{~mL}$ of nest extract to $40 \mathrm{~mL}$ of $1 \mathrm{mM}$ of silver nitrate $\left(\mathrm{AgNO}_{3}\right)$ solution. UV, FTIR, EDX, and TEM were used for the characterization of fabricated-AgNPs. These particles show wide applications like antimicrobial activity against $P$. aeruginosa and $K$. granulomatis (at concentrations of 60,80 , and $100 \mu \mathrm{g} / \mathrm{mL}$ ), the particles $100 \mu \mathrm{g} / \mathrm{mL}$ show $100 \%$ inhibition for Aspergillus flavus and Aspergillus niger. Furthermore, at 20 and $40 \mu \mathrm{g} / \mathrm{mL}$, malachite green degradation was reported to be $64.3 \%-93.1 \%$ within $24 \mathrm{~h}$ of application; they also exhibited excellent blood anticoagulation and blood clot dissolution [142]. Additionally, the mud dauber wasp-associated fungus, Talaromyces sp. (CMB-W045), could be used to recover $\mathrm{Fe}_{2} \mathrm{O}_{3}$ nanoparticles from natural extracts [20].

Since two decades ago, some peptides (CPPs; cell-penetrating peptides) have been used in drug delivery applications as nano-carriers for macromolecule delivery systems as they can penetrate living cells. Among CPPs, there is a chimeric peptide called transportan (TP), which consists of 27 amino acids derived from a fusion of the first 12 residues of $\mathrm{N}$-terminus of neuropeptide galanin and lysine residues, thus binding the remaining 14 C-terminal residues of mastoparan, a wasp venom peptide [143]. Subsequently, TP with d-arginine was used to synthesize a 36 amino acid peptide called T9 (dR). T9 (dR) can condense siRNA into nanoparticles sized between 350 and $550 \mathrm{~nm}$ and is also used for siRNA delivery into different cells; and to inhibit the replication of the influenza virus [144]. A similar study showed that TP nanoparticles could be used to improve cutaneous paclitaxel delivery and three-dimensional (3D)-bioengineered skin against tumor cancer cell lines [21]. Regarding the application of peptides in fields like agriculture nanobiotechnology, many CPPs can translocate macromolecular cargo complexes of drugs, 
proteins, or nucleic acids that are much larger than the pores of plasma membranes inside plant cells, which can lead to a potential revolution in the field of cell biotechnology [143].

\section{Wasp Venom, Allergies, and Sensitization: A Double-Edged Sword}

Wasp venom may result in anaphylaxis, anaphylactic shock, or even death $[145,146]$. Compared to airborne allergens such as mites and pollen [147], wasp venom is injected into the skin, reaching the blood directly, and initiating a general immune response [145]. The most frequent clinical picture starts with swelling at the sting site, expands over a $10-\mathrm{cm}$-diameter, and lasts for longer than $24 \mathrm{~h}$ in approximately $15-20 \%$ of the general population [148]. Venom allergy can cause various reactions, categorized as common local, wide local, systemic anaphylactic, systemic toxic, and rare reactions [149]. Up to $3 \%$ of the population suffers from potentially either systematic, anaphylactic, or toxic reactions after wasp stings [150], which could be life-threatening and lead to sudden death Approximately fifty fatalities from wasp stings are reported every year [151]. Phospholipase A1 (Ves $v$ 1), hyaluronidase (Ves $\vee 2$ ), protease vitellogenin (Ves $\vee 6$ ), and antigen 5 (Ves v 5) are the most allergenic components of the genera Dolichovespula, Polistes, Vespula, and Vespa [152-154]. Phospholipase A1, hyaluronidase, and antigen 5 are the three main allergens described for P. paulista venom and cause a high number of allergic reactions and dozens of fatal anaphylaxis cases annually in Brazil [155-157].

Accurate diagnosis of venom allergy is largely based on history, skin testing, radioallergosorbent test (RAST), the identification of particular IgE (sIgE) antibodies and basophilic activation testing (BAT), and is thus contingent on the choice of allergen-directed immunotherapy (AIT) [158-160]. The skin test is considered the golden standard diagnostic test due to its sensitivity to different types of venom, its ability to give results within a few minutes and to simulate a sting's real-life effects better than in vitro tests. Recombinant allergen-based BAT testing is a highly specific but sometimes less sensitive tool. The severity of sting reactions was inversely correlated with total IgE levels [161-163], negative skin test results and non-detectable IgE despite BAT positivity were seen in $73 \%$ of patients following an insect sting and were associated with a systemic allergic reaction. Component-resolved assessments are a beneficial addition to the diagnostic continuum as long as they are used in accordance with existing procedures. Commercially available recombinant allergens have modern processes operating, such as spiking yellow jacket venom (YJV) extract with Ves $\mathrm{v} 5$, providing increased exposure to the initial allergen detectors [164]. Recently, rPoly p 1 (recombinant of phospholipase A1 (PLA1)) was known as marker of $P$. paulista allergy with high sensitivity of $95 \%$ [165].

Emergency medicines and venom immunotherapy (VIT) are two main therapeutic options to treat wasp venom allergy [145]. Emergency medicine refers to administering antihistamines, epinephrine (adrenaline), and corticosteroids to patients with wasp venom allergies. First-line treatment of VIT is recommended. VIT is extremely effective in enhancing patients' quality of life and greatly decreasing the risk of systemic responses before and after therapy [145]. VIT includes venom injections with an up-dosing period over several weeks and a 3-5 year maintenance period. VIT is considered safe as most adverse events are mild and local during the induction and maintenance period [166]. However, a significant medication period ( $3-5$ years) results in high costs and low adherence to the therapy. In order to overcome this hindrance, a clinical routine has been introduced with ultra-rush protocols for up-dosing in just a few hours. Ultra-rush therapy is safe, quick, and compliant, and therefore cost-effective [23,166,167].

Another major challenge facing VIT is cross-reactivity. Cross-reactivity can occur due to similarities in the content and composition of Vespula species of single allergen venom. Vespinae (Vespula, Vespa, and Dolichovespula) have high cross-reactivity with each other but are less cross-reactive than Polistes. Compared to American species, crossreactivity between European Polistes species is generally very high [153]. Cross-reactivity among venoms of different species may be a testing challenge [168]. False or positive cross-reaction outcomes can occur when IgE is directed toward antigenic carbohydrate 
determinants [169]. Seven recombinant antigens 5 of the Vespoidea groups were engineered and tested to resolve immunological IgE cross-reactivity at the molecular level [170].

Therefore, the measurement of specific IgE (sIgE) antibodies plays a major role. Immunoglobulin $\mathrm{E}(\mathrm{IgE})$ antibodies are the main actors, causing histamine release, lipid mediators, enzymes, cytokines, and chemokines responsible for the acute allergic response [171]. Component-resolved diagnosis (CRD) has been established recently, allowing the measurement of sIgE antibodies against Ves v1, Ves v5, and Pol d5, as well as cross-reactive carbohydrate determinants (CCDs). Estimations of IgE antibodies to Ves $v$ 1, in addition to Ves v 5, should be included in diagnostic work [172]. Ves $\mathrm{v} 5$ and Pol d 5 are 23-kDa proteins present in the Vespidae family of venom hornet (Vespula spp.) and wasp (Polistes dominulus) venom. Both proteins are known as antigen 5 and are recognized as the largest and most active allergens [173]. These tests were designed to help evaluate the therapeutic validity of any given sensitization, especially in patients with dual sensitization.

Several studies have been conducted to compare the immunoprotective efficacy and safety of different wasp venom preparations. In 1986, and for the first time, Mosbech and colleagues investigated the allergen immunotherapy effectiveness of yellow jacket wasp venom with three different preparations using thirty-two yellow jacket venom-allergic patients. The preparations were YJ Pharmalgen (YJ venom reconstituted in albumin containing saline diluent), $\mathrm{YJ}$ venom extract adsorbed to aluminum hydroxide, and $\mathrm{YJ}$ venom extract non-adsorbed. The results demonstrated that the three extracts showed the same immunological effectiveness (the amount of specific IgG was $44.2 \pm 3.8 \mu \mathrm{g} / \mathrm{mL}$ ) except for some minor varieties representation in IgG response induction for a longer period treatment with aluminum hydroxide-adsorbed extract [174,175].

\section{Concluding Remarks}

A limited number of ingredients in venom have been defined despite the wide diversity of wasp species. Wasps can synthesize toxic compounds as a part of their prey control mechanism to capture prey and defend their colonies. The venomous components of predator wasps are a complex mixture of high molecular weight proteins (e.g., enzymes and allergens), small peptides, and low molecular weight compounds (e.g., bioactive amino acids and amines). The accessibility of extremely delicate techniques, such as mass spectrometry, enables a more effective assessment of proteomics and transcriptomics of a restricted number of venoms to understand their impacts. For use in the medical sector, these compounds are promising as each compound was described by its effects, such as antimicrobial, anticancer, histamine release, and anti-inflammatory ability. Accumulating functional information on venom component bioactivity would promote the use of wasp venoms for pharmacological and medical purposes. Moreover, synthesis protocols should be developed to provide a higher quantity of active compounds for further evaluation in order to be applied in the industry. Some issues hinder its effective application, such as allergies to wasp venom, and restricted extraction amount. Many attempts have been made to reduce venomous side effects using VIT, which acts as a basic treatment for patients allergic to hymenopteran venom. VIT improved patient quality of life by reducing the risk of systemic reactions during, and after treatment.

Considering the numerous studies that have been conducted on wasp venom little has been reported on the practical application of these compounds. Among the wasp components, the antimicrobial properties of mastoparan are the most tested and confirmed [41]. Moreover, several wasp venom proteins have been registered in drug banks for use in allergenic testing, including proteins from Polistes metrics [176], Polistes exclamans [177], Vespula germanica [178], Polistes fuscatu [179], V. vulgaris [180], Dolichovespula arenaria [181], Dolichovespula maculate [182], Vespula pensylvanica [183], and Vespula maculifrons [184].

Although wasp venom remains mostly unexplored, recent findings have shown that venom is also abundant in peptides, and these peptides are similar to other venomous species. Up to 134 venom peptides have been entirely sequenced to date (Table 1 ). The pharmacological properties of insect venom peptides are identified as antimicrobial. 
Author Contributions: Conceptualization, H.R.E.-S.; validation, H.R.E.-S. and S.A.M.K.; writingoriginal draft preparation, H.H.S., A.A.E.-W. and N.Y.; writing-review and editing, M.D., A.F.M.A., C.Z., A.H.A., H.E.T., S.H.D.M., M.M.A.-D., S.G.M., I.E.-G., G.K., Y.A.N., S.A.M.K. and H.R.E.-S.; supervision, H.R.E.-S.; funding acquisition, H.R.E.-S. All authors have read and agreed to the published version of the manuscript.

Funding: This work was supported by Swedish Research links Grant VR 2016-05885.

Institutional Review Board Statement: Not applicable.

Informed Consent Statement: Not applicable.

Data Availability Statement: No new data were created or analyzed in this study. Data sharing is not applicable to this article.

Acknowledgments: Authors are very grateful to the Swedish Research links Grant VR 2016-05885 and the Department of Molecular Biosciences, Wenner-Grens Institute, Stockholm University, Sweden, for the financial support.

Conflicts of Interest: The authors declare no conflict of interest.

\section{References}

1. Konno, K.; Kazuma, K.; Nihei, K. Peptide toxins in solitary wasp venoms. Toxins 2016, 8, 114. [CrossRef]

2. Lin, Z.; Cheng, Y.; Wang, R.J.; Du, J.; Volovych, O.; Li, J.C.; Hu, Y.; Lu, Z.Y.; Lu, Z.; Zou, Z. A metalloprotease homolog venom protein from a parasitoid wasp suppresses the toll pathway in host hemocytes. Front. Immunol. 2018, 9, 2301-2315. [CrossRef]

3. Gong, J.; Yuan, H.; Gao, Z.; Hu, F. Wasp venom and acute kidney injury: The mechanisms and therapeutic role of renal replacement therapy. Toxicon 2019, 163, 1-7. [CrossRef]

4. Kim, Y.; Son, M.; Noh, E.Y.; Kim, S.; Kim, C.; Yeo, J.H.; Park, C.; Lee, K.W.; Bang, W.Y. MP-V1 from the venom of social wasp Vespula vulgaris is a de novo type of mastoparan that displays superior antimicrobial activities. Molecules 2016, 21, 512. [CrossRef]

5. Chen, W.; Yang, X.; Yang, X.; Zhai, L.; Lu, Z.; Liu, J.; Yu, H. Antimicrobial peptides from the venoms of Vespa bicolor Fabricius. Peptides 2008, 29, 1887-1892. [CrossRef] [PubMed]

6. Wu, R.; Li, D.; Tang, Q.; Wang, W.; Xie, G.; Dou, P. A novel peptide from Vespa ducalis induces apoptosis in osteosarcoma cells by activating the p38 mapk and jnk signaling pathways. Biol. Pharm. Bull. 2018, 41, 458-464. [CrossRef] [PubMed]

7. Danneels, E.L.; Gerlo, S.; Heyninck, K.; Van Craenenbroeck, K.; De Bosscher, K.; Haegeman, G.; De Graaf, D.C. How the venom from the ectoparasitoid wasp Nasonia vitripennis exhibits anti-inflammatory properties on mammalian cell lines. PLoS ONE 2014, 9, e96825. [CrossRef]

8. Torres, M.D.T.; Silva, A.F.; Andrade, G.P.; Pedron, C.N.; Cerchiaro, G.; Ribeiro, A.O.; Oliveira, V.X.; de la Fuente-Nunez, C. The wasp venom antimicrobial peptide polybia-CP and its synthetic derivatives display antiplasmodial and anticancer properties. Bioeng. Transl. Med. 2020, 5, e10167. [CrossRef] [PubMed]

9. Vila-Farrés, X.; López-Rojas, R.; Pachón-Ibáñez, M.E.; Teixidó, M.; Pachón, J.; Vila, J.; Giralt, E. Sequence-activity relationship, and mechanism of action of mastoparan analogues against extended-drug resistant Acinetobacter baumannii. Eur. J. Med. Chem. 2015, 101, 34-40. [CrossRef]

10. Chionis, K.; Krikorian, D.; Koukkou, A.; Sakarellos-daitsiotis, M.; Panou-pomonis, E. Synthesis and biological activity of lipophilic analogs of the cationic antimicrobial active peptide anoplin. Pept. Sci. 2016, 22, 731-736. [CrossRef]

11. Torres, M.D.T.; Pedron, C.N.; da Silva Lima, J.A.; da Silva, P.I.; da Silva, F.D.; Oliveira, V.X. Antimicrobial activity of leucinesubstituted decoralin analogs with lower hemolytic activity. J. Pept. Sci. 2017, 23, 818-823. [CrossRef]

12. Wang, K.; Zhang, B.; Zhang, W.; Yan, J.; Li, J.; Wang, R. Antitumor effects, cell selectivity and structure-activity relationship of a novel antimicrobial peptide polybia-MPI. Peptides 2008, 29, 963-968. [CrossRef]

13. Wang, K.; Jia, F.; Dang, W.; Zhao, Y.; Zhu, R. Antifungal effect and action mechanism of antimicrobial peptide polybia-CP. Pept. Sci. 2016, 22, 28-35. [CrossRef] [PubMed]

14. Wang, K.; Yan, J.; Liu, X.; Zhang, J.; Chen, R.; Zhang, B.; Dang, W.; Zhang, W.; Kai, M.; Song, J.; et al. Novel cytotoxity exhibition mode of polybia-CP, a novel antimicrobial peptide from the venom of the social wasp Polybia paulista. Toxicology 2011, 288, 27-33. [CrossRef]

15. Coutinho, R.; Trentini, M.M.; De Castro, J.; Simon, K.S.; Bocca, A.L.; Silva, L.P.; Mortari, R.; Kipnis, A.; Junqueira-Kipnis, A.P. Antimycobacterial activity of a new peptide polydim-I isolated from Neotropical social wasp Polybia dimorpha. PLoS ONE 2016, 11, e0149729.

16. Gonçalves, J.; Rangel, M.; Biolchi, A.; Alves, E.; Moreira, K.; Silva, L.; Mortari, M. Antinociceptive properties of the mastoparan peptide Agelaia-MPI isolated from social wasps. Toxicon 2016, 120, 15-21. [CrossRef] [PubMed]

17. Da Silva, A.V.R.; De Souza, B.M.; Dos Santos Cabrera, M.P.; Dias, N.B.; Gomes, P.C.; Neto, J.R.; Stabeli, R.G.; Palma, M.S. The effects of the C-terminal amidation of mastoparans on their biological actions and interactions with membrane-mimetic systems. Biochim. Biophys. Acta-Biomembr. 2014, 1838, 2357-2368. [CrossRef] 
18. Hilchie, A.L.; Sharon, A.J.; Haney, E.F.; Hoskin, D.W.; Bally, M.B.; Franco, O.L.; Corcoran, J.A.; Hancock, R.E.W. Mastoparan is a membranolytic anti-cancer peptide that works synergistically with gemcitabine in a mouse model of mammary carcinoma. Biochim. Biophys. Acta-Biomembr. 2016, 1858, 3195-3204. [CrossRef]

19. Jalaei, J.; Layeghi-Ghalehsoukhteh, S.; Hosseini, A.; Fazeli, M. Antibacterial effects of gold nanoparticles functionalized with the extracted peptide from Vespa orientalis wasp venom. J. Pept. Sci. 2018, 24, e3124-e3133. [CrossRef]

20. Kalansuriya, P.; Quezada, M.; Espósito, B.P.; Capon, R.J. Talarazines A-E: Noncytotoxic iron (III) chelators from an Australian mud dauber wasp-associated fungus, talaromyces sp. (CMB-W045). J. Nat. Prod. 2017, 80, 609-615. [CrossRef]

21. Pepe, D.; Carvalho, V.F.M.; McCall, M.; de Lemos, D.P.; Lopes, L.B. Transportan in nanocarriers improves skin localization and antitumor activity of paclitaxel. Int. J. Nanomed. 2016, 11, 2009-2019.

22. Perkins, J.B.; Yates, A.B. Allergy to stinging insects: Diagnosis and management. EMJ Allergy Immunol. 2018, 3, 99-105.

23. Pospischil, I.M.; Kagerer, M.; Cozzio, A.; Angelova-Fischer, I.; Guenova, E.; Ballmer-Weber, B.; Hoetzenecker, W. Comparison of the safety profiles of 3 different Hymenoptera venom immunotherapy protocols: A retrospective 2-center study of 143 patients. Int. Arch. Allergy Immunol. 2020, 181, 783-789. [CrossRef]

24. Sahiner, U.M.; Durham, S.R. Hymenoptera venom allergy: How does venom immunotherapy prevent anaphylaxis from bee and wasp stings? Front. Immunol. 2019, 10, 1959-1966. [CrossRef]

25. Baracchi, D.; Tragust, S. Venom as a component of external immune defense. In Evolution of Venomous Animals and Their Toxins; Gopalakrishnakone, P., Malhotra, A., Eds.; Springer Nature Switzerland AG: Cham, Switzerland, 2017; Volume 11, pp. 213-233. ISBN 9789400764583

26. Chen, X.; Zhang, L.; Wu, Y.; Wang, L.; Ma, C.; Xi, X.; Bininda-Emonds, O.R.P.; Shaw, C.; Chen, T.; Zhou, M. Evaluation of the bioactivity of a mastoparan peptide from wasp venom and of its analogues designed through targeted engineering. Int. J. Biol. Sci. 2018, 14, 599-607. [CrossRef]

27. Danneels, E.L.; Formesyn, E.M.; de Graaf, D.C. Exploring the potential of venom from Nasonia vitripennis as therapeutic agent with high-throughput screening tools. Toxins 2015, 7, 2051-2070. [CrossRef]

28. Czaikoski, P.G.; Menaldo, D.L.; Marcussi, S.; Baseggio, A.L.; Fuly, A.L.; Paula, R.C.; Quadros, A.U.; Romao, P.R.; Buschini, M.L.; Cunha, F.Q.; et al. Anticoagulant and fibrinogenolytic properties of the venom of Polybia occidentalis social wasp. Blood Coagul. Fibrinolysis 2010, 21, 653-659. [CrossRef]

29. Hoshina, M.M.; Santos, L.D.; Palma, M.S.; Marin-morales, M.A. Cytotoxic, genotoxic/antigenotoxic and mutagenic/antimutagenic effects of the venom of the wasp Polybia paulista. Toxicon 2013, 72, 64-70. [CrossRef] [PubMed]

30. Yang, X.; Wang, Y.; Lee, W.H.; Zhang, Y. Antimicrobial peptides from the venom gland of the social wasp Vespa tropica. Toxicon 2013, 74, 151-157. [CrossRef] [PubMed]

31. Jalaei, J.; Fazeli, M.; Rajaian, H.; Shekarforoush, S.S. In vitro antibacterial effect of wasp (Vespa orientalis) venom. J. Venom. Anim. Toxins Incl. Trop. Dis. 2014, 20, 22-27. [CrossRef]

32. Baracchi, D.; Mazza, G.; Turillazzi, S. From individual to collective immunity: The role of the venom as antimicrobial agent in the Stenogastrinae wasp societies. J. Insect Physiol. 2011, 58, 188-193. [CrossRef] [PubMed]

33. Pålsson-McDermott, E.M.; O'Neill, L.A.J. Targeting immunometabolism as an anti-inflammatory strategy. Cell Res. 2020, 30, 300-314. [CrossRef]

34. Kaushik, D.K.; Thounaojam, M.C.; Mitra, A.; Basu, A. Vespa tropica venom suppresses lipopolysaccharide-mediated secretion of pro-inflammatory cyto-chemokines by abrogating nuclear factor-k B activation in microglia. Inflamm. Res. 2014, 63, 657-665. [CrossRef]

35. Saba, E.; Shafeeq, T.; Irfan, M.; Lee, Y.Y.; Kwon, H.W.; Seo, M.G.; Park, S.J.; Lee, K.Y.; Rhee, M.H. Anti-inflammatory activity of crude venom isolated from parasitoid wasp, Bracon hebetor Say. Mediat. Inflamm. 2017, 2017, 1-11. [CrossRef] [PubMed]

36. Danneels, E.L.; Rivers, D.B.; de Graaf, D.C. Venom proteins of the parasitoid wasp Nasonia vitripennis: Recent discovery of an untapped pharmacopee. Toxins 2010, 2, 494-516. [CrossRef] [PubMed]

37. De Castro e Silva, J.; Lopes do Couto, L.; de Oliveira Amaral, H.; Maria Medeiros Gomes, F.; Avohay Alves Campos, G.; Paulino Silva, L.; Renata Mortari, M. Neuropolybin: A new antiseizure peptide obtained from wasp venom. Biochem. Pharmacol. 2020, 181, 114119. [CrossRef] [PubMed]

38. De Azevedo, R.A.; Figueiredo, C.R.; Ferreira, A.K.; Matsuo, A.L.; Massaoka, M.H.; Girola, N.; Auada, A.V.; Farias, C.F.; Pasqualoto, K.F.; Rodrigues, C.P.; et al. Mastoparan induces apoptosis in B16F10-Nex2 melanoma cells via the intrinsic mitochondrial pathway and displays antitumor activity in vivo. Peptides 2015, 68, 113-119. [CrossRef]

39. Hirai, Y.; Ueno, Y.; Yasuhara, T.; Yoshida, H.; Nakajima, T. A new mast cell degranulating peptide, polistes mastoparan, in the venom of Polistes jadwigae. Biomed. Res. 1980, 1, 185-187. [CrossRef]

40. Da Silva, A.M.B.; Silva-Gonçalves, L.C.; Oliveira, F.A.; Arcisio-Miranda, M. Pronecrotic activity of cationic mastoparan peptides in human glioblastoma multiforme cells via membranolytic action. Mol. Neurobiol. 2018, 55, 5490-5504. [CrossRef]

41. Vila-Farres, X.; Garcia de la Maria, C.; López-Rojas, R.; Pachón, J.; Giralt, E.; Vila, J. In vitro activity of several antimicrobial peptides against colistin-susceptible and colistin-resistant Acinetobacter baumannii. Clin. Microbiol. Infect. 2012, 18, 383-387. [CrossRef]

42. Mizuno, K.; Nakahata, N.; Ohizumi, Y. Characterization of mastoparan-induced histamine release from RBL-2H3 cells. Toxicon 1998, 36, 447-456. [CrossRef] 
43. Yamada, Y.; Shinohara, Y.; Kakudo, T.; Chaki, S.; Futaki, S.; Kamiya, H.; Harashima, H. Mitochondrial delivery of mastoparan with transferrin liposomes equipped with a pH-sensitive fusogenic peptide for selective cancer therapy. Int. J. Pharm. 2005, 303, 1-7. [CrossRef]

44. Nakahata, N.; Imata, K.; Okawa, T.; Watanabe, Y.; Ishimoto, H.; Ono, T.; Ohizumi, Y.; Nakanishi, H. Mastoparan elicits prostaglandin $\mathrm{E} 2$ generation and inhibits inositol phosphate accumulation via different mechanisms in rabbit astrocytes Norimichi. Biochim. Biophys. Acta (BBA)-Molecular Cell Res. 1996, 1310, 60-66. [CrossRef]

45. Irazazabal, L.N.; Porto, W.F.; Ribeiro, S.M.; Casale, S.; Humblot, V.; Ladram, A.; Franco, O.L. Selective amino acid substitution reduces cytotoxicity of the antimicrobial peptide mastoparan. Biochim. Biophys. Acta-Biomembr. 2016, 1858, 2699-2708. [CrossRef] [PubMed]

46. De Souza, B.M.; Cabrera, M.P.D.S.; Gomes, P.C.; Dias, N.B.; Stabeli, R.G.; Leite, N.B.; Neto, J.R.; Palma, M.S. Structure-activity relationship of mastoparan analogs: Effects of the number and positioning of Lys residues on secondary structure, interaction with membrane-mimetic systems and biological activity. Peptides 2015, 72, 164-174. [CrossRef] [PubMed]

47. Galeane, M.C.; Gomes, P.C.; De L Singulani, J.; De Souza, B.M.; Palma, M.S.; Mendes-Giannini, M.J.S.; Almeida, A.M.F. Study of mastoparan analog peptides against Candida albicans and safety in zebrafish embryos (Danio rerio). Future Microbiol. 2019, 14, 1087-1097. [CrossRef] [PubMed]

48. Ha, Y.J.; Kim, S.W.; Lee, C.W.; Bae, C.H.; Yeo, J.H.; Kim, I.S.; Gal, S.W.; Hur, J.; Jung, H.K.; Kim, M.J.; et al. Anti-Salmonella activity modulation of mastoparan V1-A wasp venom toxin-Using protease inhibitors, and its efficient production via an Escherichia coli secretion system. Toxins 2017, 9, 321. [CrossRef]

49. Ho, C.L.; Hwang, L.L. Structure and biological activities of a new mastoparan isolated from the venom of the hornet Vespa basalis. Biochem. J. 1991, 274, 453-456. [CrossRef]

50. Ho, C.L.; Hwang, L.L.; Lin, Y.L.; Chen, C.T.; Yu, H.M.; Wang, K.T. Cardiovascular effects of mastoparan B and its structural requirements. Eur. J. Pharmacol. 1994, 259, 259-264. [PubMed]

51. Park, N.G.; Yamato, Y.; Lee, S.; Sugihara, G. Interaction of mastoparan-B from venom of a hornet in taiwan with phospholipid bilayers and its antimicrobial activity. Biopolymers 1995, 36, 793-801. [CrossRef]

52. Hirai, Y.; Yasuhara, T.; Yoshida, H.; Nakajima, T. A new mast cell degranulating peptide, mastoparan-M, in the venom of the hornet Vespa mandarinia. Biomed. Res. 1981, 2, 447-449. [CrossRef]

53. Wu, T.M.; Chou, T.C.; Ding, Y.A.; Li, M.L. Stimulation of TNF- $\alpha$, IL-1 $\beta$ and nitrite release from mouse cultured spleen cells and lavaged peritoneal cells by mastoparan M. Immunol. Cell Biol. 1999, 77, 476-482. [CrossRef]

54. Li, M.; Liao, R.; Qiu, J.; Wang, Z.; Wu, T. Antimicrobial activity of synthetic all- D mastoparan M. Int. J. Antimicrob. Agents 2000, 13, 203-208. [CrossRef]

55. Konno, K.; Hisada, M.; Fontana, R.; Lorenzi, C.C.B.; Naoki, H.; Itagaki, Y.; Miwa, A.; Kawai, N.; Nakata, Y.; Yasuhara, T.; et al. Anoplin, a novel antimicrobial peptide from the venom of the solitary wasp Anoplius samariensis. Biochim. Biophys. Acta-Protein Struct. Mol. Enzymol. 2001, 1550, 70-80. [CrossRef]

56. Zhu, L.; Fu, C.; Zhang, S.; Chen, W.; Jin, Y. Novel cytotoxic exhibition mode of antimicrobial peptide anoplin in MEL cells, the cell line of murine Friend leukemia virus-induced leukemic cells. Pept. Sci. 2013, 19, 566-574. [CrossRef] [PubMed]

57. Ifrah, D.; Doisy, X.; Ryge, T.S.; Hansen, P.R. Structure-activity relationship study of anoplin. J. Pept. Sci. 2005, 11, 113-121. [CrossRef] [PubMed]

58. Perez, M.; Santos, D.O.S.; Arcisio-miranda, M.; Broggio, T.; Ruggiero, R.; Ao, J.O. Study of the mechanism of action of anoplin, a helical antimicrobial decapeptide with ion channel-like activity, and the role of the amidated C -terminus. J. Pept. Sci. 2008, 661-669.

59. Won, A.; Khan, M.; Gustin, S.; Akpawu, A.; Seebun, D.; Avis, T.J.; Leung, B.O.; Hitchcock, A.P.; Ianoul, A. Investigating the effects of L- to D-amino acid substitution and deamidation on the activity and membrane interactions of antimicrobial peptide anoplin. Biochim. Biophys. Acta-Biomembr. 2011, 1808, 1592-1600. [CrossRef] [PubMed]

60. Wang, Y.; Chen, J.; Zheng, X.; Yang, X.; Ma, P.; Cai, Y.; Zhang, B.; Chen, Y. Design of novel analogues of short antimicrobial peptide anoplin with improved antimicrobial activity. J. Pept. Sci. 2014, 20, 945-951. [CrossRef] [PubMed]

61. Konno, K.; Rangel, M.; Oliveira, J.S.; dos Santos Cabrera, M.P.; Fontana, R.; Hirata, I.Y.; Hide, I.; Nakata, Y.; Mori, K.; Kawano, M.; et al. Decoralin, a novel linear cationic $\alpha$-helical peptide from the venom of the solitary eumenine wasp Oreumenes decoratus. Peptides 2007, 28, 2320-2327. [CrossRef]

62. Torres, M.D.T.; Andrade, G.P.; Sato, R.H.; Pedron, C.N.; Manieri, T.M.; Cerchiaro, G.; Ribeiro, A.O.; de la Fuente-Nunez, C.; Oliveira, V.X. Natural and redesigned wasp venom peptides with selective antitumoral activity. Beilstein J. Org. Chem. 2018, 14, 1693-1703. [CrossRef] [PubMed]

63. Torres, M.D.T.; Pedron, C.N.; Araújo, I.; Silva, P.I.; Silva, F.D.; Oliveira, V.X. Decoralin analogs with increased resistance to degradation and lower hemolytic activity. ChemistrySelect 2017, 2, 18-23. [CrossRef]

64. Torres, M.D.T.; Silva, A.F.; Pedron, C.N.; Capurro, M.L. Peptide design enables reengineering of an inactive wasp venom peptide into synthetic antiplasmodial agents. ChemistrySelect 2018, 3, 5859-5863. [CrossRef]

65. Ribeiro, S.P.; Mendes, M.A.; Dos Santos, L.D.; De Souza, B.M.; Marques, M.R.; De Azevedo, W.F.; Palma, M.S. Structural and functional characterization of N-terminally blocked peptides isolated from the venom of the social wasp Polybia paulista. Peptides 2004, 25, 2069-2078. [CrossRef] 
66. Luong, H.X.; Kim, D.H.; Lee, B.J.; Kim, Y.W. Antimicrobial activity and stability of stapled helices of polybia-MP1. Arch. Pharm. Res. 2017, 40, 1414-1419. [CrossRef]

67. Dos Santos Cabrera, M.P.; Arcisio-Miranda, M.; Gorjão, R.; Leite, N.B.; De Souza, B.M.; Curi, R.; Procopio, J.; Ruggiero Neto, J.; Palma, M.S. Influence of the bilayer composition on the binding and membrane disrupting effect of polybia-MP1, an antimicrobial mastoparan peptide with leukemic T-lymphocyte cell selectivity. Biochemistry 2012, 51, 4898-4908. [CrossRef]

68. Brigatte, P.; Cury, Y.; De Souza, B.M.; Baptista-Saidemberg, N.B.; Saidemberg, D.M.; Gutierrez, V.P.; Palma, M.S. Hyperalgesic and edematogenic effects of peptides isolated from the venoms of honeybee (Apis mellifera) and neotropical social wasps (Polybia paulista and Protonectarina sylveirae). Amino Acids 2011, 40, 101-111. [CrossRef]

69. De Souza, B.M.; Dos Santos Cabrera, M.P.; Neto, J.R.; Palma, M.S. Investigating the effect of different positioning of lysine residues along the peptide chain of mastoparans for their secondary structures and biological activities. Amino Acids 2011, 40, 77-90. [CrossRef]

70. Wang, K.; Yan, J.; Dang, W.; Liu, X.; Chen, R.; Zhang, J.; Zhang, B.; Zhang, W.; Kai, M.; Yan, W.; et al. Membrane active antimicrobial activity and molecular dynamics study of a novel cationic antimicrobial peptide polybia-MPI, from the venom of Polybia paulista. Peptides 2013, 39, 80-88. [CrossRef]

71. Wang, K.; Yan, J.; Dang, W.; Xie, J.; Yan, B.; Yan, W.; Sun, M.; Zhang, B.; Ma, M.; Zhao, Y.; et al. Dual antifungal properties of cationic antimicrobial peptides polybia-MPI: Membrane integrity disruption and inhibition of biofilm formation. Peptides 2014, 56, 22-29. [CrossRef]

72. Wang, K.; Yan, J.; Chen, R.; Dang, W.; Zhang, B.; Zhang, W.; Song, J.; Wang, R. Membrane-active action mode of polybia-CP, a novel antimicrobial peptide isolated from the venom of Polybia paulista. Antimicrob. Agents Chemother. 2012, 56, 3318-3323. [CrossRef]

73. Rangel, M.; Dos Santos Castro, F.F.; Mota-Lima, L.D.; Clissa, P.B.; Martins, D.B.; Dos Santos Cabrera, M.P.; Mortari, M.R. Polydim-I antimicrobial activity against MDR bacteria and its model membrane interaction. PLoS ONE 2017, 12, e0178785. [CrossRef]

74. Mendes, M.A.; De Souza, B.M.; Marques, M.R.; Palma, M.S. Structural and biological characterization of two novel peptides from the venom of the neotropical social wasp Agelaia pallipes pallipes. Toxicon 2004, 44, 67-74. [CrossRef] [PubMed]

75. Wang, K.; Yan, J.; Chen, R.; Dang, W.; Zhang, B.; Zhang, W.; Song, J.; Wang, R.; Yan, J.; Chen, R.; et al. Membrane perturbation action mode and structure-activity relationships of protonectin, a novel antimicrobial peptide from the venom of the neotropical social wasp Agelaia pallipes pallipes. Antimicrob. Agents Chemother. 2013, 56, 4632-4639. [CrossRef] [PubMed]

76. Wang, F.; Manku, S.; Hall, D.G. Solid phase syntheses of polyamine toxins HO-416b and PhTX-433. Use of an efficient polyamide reduction strategy that facilitates access to branched analogues. Org. Lett. 2000, 2, 1581-1583. [CrossRef] [PubMed]

77. Choi, S.K.; Kalivretenos, A.G.; Usherwood, P.N.R.; Nakanishi, K. Labeling studies of photolabile philanthotoxins with nicotinic acetylcholine receptors: Mode of interaction between toxin and receptor. Chem. Biol. 1995, 2, 23-32. [CrossRef]

78. Kachel, H.S.; Franzyk, H.; Mellor, I.R. Philanthotoxin analogues that selectively inhibit ganglionic nicotinic acetylcholine receptors with exceptional potency. J. Med. Chem. 2019, 62, 6214-6222. [CrossRef] [PubMed]

79. Crandall, Y.M.; Bruch, M.D. Characterization of the structure and dynamics of mastoparan-X during folding in a TFE by CD and NMR spectroscopy. Biopolymers 2007, 89, 197-209. [CrossRef] [PubMed]

80. Henriksen, J.R.; Etzerodt, T.; Gjetting, T.; Andresen, T.L. Side chain hydrophobicity modulates therapeutic activity and membrane selectivity of antimicrobial peptide mastoparan-X. PLoS ONE 2014, 9, e91007. [CrossRef]

81. Konno, K.; Hisada, M.; Naoki, H.; Itagaki, Y.; Kawai, N.; Miwa, A.; Yasuhara, T.; Morimoto, Y.; Nakata, Y. Structure and biological activities of eumenine mastoparan-AF (EMP-AF), a new mast cell degranulating peptide in the venom of the solitary wasp (Anterhynchium flavomarginatum micado). Toxicon 2000, 38, 1505-1515. [CrossRef]

82. Ramon, R.; De Souza, B.M.; Havt, A.; Mario, S.; Pires, R.; Lins, E.; Albuquerque, D.; Nogueira, V.; Maria, A.; Martins, C. Trypanocidal activity of mastoparan from Polybia paulista wasp venom by interaction with TcGAPDH. Toxicon 2017, 137, 168-172.

83. Xu, X.; Li, J.; Lu, Q.; Yang, H.; Zhang, Y.; Lai, R. Two families of antimicrobial peptides from wasp (Vespa magnifica) venom. Toxicon 2006, 47, 249-253. [CrossRef] [PubMed]

84. Hisada, M.; Konno, K.; Itagaki, Y.; Naoki, H.; Nakajima, T. Sequencing wasp venom peptides by endopeptidase digestion and nested collision-induced dissociation/post-source decay methods. Rapid Commun. Mass Spectrom. 2002, 16, 1040-1048. [CrossRef]

85. Parkinson, N.; Smith, I.; Audsley, N.; Edwards, J. Purification of pimplin, a paralytic heterodimeric polypeptide from venom of the parasitoid wasp Pimpla hypochondriaca, and cloning of the cDNA encoding one of the subunits. Insect Biochem. Mol. Biol. 2002, 32, 1769-1773. [CrossRef]

86. Hisada, M.; Konno, K.; Itagaki, Y.; Naoki, H.; Nakajima, T. Advantages of using nested collision induced dissociation/post-source decay with matrix-assisted laser desorption/ionization time-of-flight mass spectrometry: Sequencing of novel peptides from wasp venom. Rapid Commun. Mass Spectrom. 2000, 14, 1828-1834. [CrossRef]

87. Pizzo, A.B.; Beleboni, R.O.; Gomes Carolino, R.O.; de Oliveira, L.; Miranda, A.; Coutinho-Netto, J.; Fontana, A.C.K.; dos Santos, W.F. Isolation and chemical characterization of agelaiatoxin8 (AvTx8) from Agelaia vicina wasp venom and its biological effects on GABA neurotransmission. J. Biochem. Mol. Toxicol. 2017, 31, e21941. [CrossRef]

88. Baptista-Saidemberg, N.B.; Saidemberg, D.M.; Palma, M.S. Profiling the peptidome of the venom from the social wasp Agelaia pallipes pallipes. J. Proteom. 2011, 74, 2123-2137. [CrossRef]

89. Konno, K.; Hisada, M.; Itagaki, Y.; Naoki, H.; Kawai, N.; Miwa, A.; Yasuhara, T.; Takayama, H. Isolation and structure of pompilidotoxins, novel peptide neurotoxins in solitary wasp venoms. Biochem. Biophys. Res. Commun. 1998, 250, 612-616. [CrossRef] [PubMed] 
90. Baptista-Saidemberg, N.B.; Saidemberg, D.M.; de Souza, B.M.; César-Tognoli, L.M.; Ferreira, V.M.; Mendes, M.A.; dos Santos Cabrera, M.P.; Neto, J.R.; Palma, M.S. Protonectin (1-6): A novel chemotactic peptide from the venom of the social wasp Agelaia pallipes pallipes. Toxicon 2010, 56, 880-889. [CrossRef]

91. Murata, K.; Shinada, T.; Ohfune, Y.; Hisada, M.; Yasuda, A.; Naoki, H.; Nakajima, T. Novel mastoparan and protonectin analogs isolated from a solitary wasp, Orancistrocerus drewseni drewseni. Amino Acids 2009, 37, 389-394. [CrossRef]

92. Gomes, P.C.; de Souza, B.M.; Dias, N.B.; Brigatte, P.; Mourelle, D.; Arcuri, H.A.; dos Santos Cabrera, M.P.; Stabeli, R.G.; Neto, J.R.; Palma, M.S. Structure-function relationships of the peptide paulistine: A novel toxin from the venom of the social wasp Polybia paulista. Biochim. Biophys. Acta (BBA)_Gen. Subj. 2014, 1840, 170-183. [CrossRef] [PubMed]

93. Argiolas, A.; Pisano, J.J. Isolation and characterization of two new peptides, mastoparan $C$ and crabrolin, from the venom of the European hornet, Vespa crabro. J. Biol. Chem. 1984, 259, 10106-10111. [CrossRef]

94. Aschi, M.; Bozzi, A.; Luzi, C.; Bouchemal, N.; Sette, M. Crabrolin, a natural antimicrobial peptide: Structural properties. J. Pept. Sci. 2017, 23, 693-700. [CrossRef]

95. Konno, K.; Hisada, M.; Naoki, H.; Itagaki, Y.; Fontana, R.; Rangel, M.; Oliveira, J.S.; dos Santos Cabrera, M.P.; Neto, J.R.; Hide, I.; et al. Eumenitin, a novel antimicrobial peptide from the venom of the solitary eumenine wasp Eumenes rubronotatus. Peptides 2006, 27, 2624-2631. [CrossRef] [PubMed]

96. Rangel, M.; dos Santos Cabrera, M.P.; Kazuma, K.; Ando, K.; Wang, X.; Kato, M.; Nihei, K.; Hirata, I.Y.; Cross, T.J.; Garcia, A.N.; et al. Chemical and biological characterization of four new linear cationic $\alpha$-helical peptides from the venoms of two solitary eumenine wasps. Toxicon 2011, 57, 1081-1092. [CrossRef] [PubMed]

97. Konno, K.; Kazuma, K.; Rangel, M.; Stolarz-de-Oliveira, J.; Fontana, R.; Kawano, M.; Fuchino, H.; Hide, I.; Yasuhara, T.; Nakata, Y. New mastoparan peptides in the venom of the solitary eumenine wasp Eumenes micado. Toxins 2019, 11, 155. [CrossRef]

98. Dias, N.B.; De Souza, B.M.; Gomes, P.C.; Brigatte, P.; Palma, M.S. Peptidome profiling of venom from the social wasp Polybia paulista. Toxicon 2015, 107, 290-303. [CrossRef]

99. Klochkov, S.G.; Pikhtelev, A.R.; Kozlovskii, V.I. A new peptide from venom of the East-European hornet Vespa orientalis. Mass spectrometric de novo sequence. Chem. Nat. Compd. 2008, 44, 63-66. [CrossRef]

100. Dos Anjos, L.C.; Gomes, F.M.M.; Do Couto, L.L.; Mourão, C.A.; Moreira, K.G.; Silva, L.P.; Mortari, M.R. Anxiolytic activity and evaluation of potentially adverse effects of a bradykinin-related peptide isolated from a social wasp venom. Life Sci. 2016, 149, 153-159. [CrossRef]

101. Andrew, K.; Kim, K.; Kim, A.; Han, Y.; Young, W. Selective anti-tumor activities of venom peptides from the lesser paper wasp Parapolybia varia. J. Asia. Pac. Entomol. 2016, 19, 821-828.

102. Yu, H.; Yang, H.; Ma, D.; Lv, Y.; Liu, T.; Zhang, K.; Lai, R.; Liu, J. Vespid chemotactic peptide precursor from the wasp, Vespa magnifica (Smith). Toxicon 2007, 50, 377-382. [CrossRef]

103. Zhou, Z. The first report of kininogen from invertebrates. Biochem. Biophys. Res. Commun. 2006, 347, 1099-1102. [CrossRef]

104. Baek, J.H.; Lee, S.H. Isolation and molecular cloning of venom peptides from Orancistrocerus drewseni (Hymenoptera: Eumenidae). Toxicon 2010, 55, 711-718. [CrossRef]

105. Baek, J.H.; Ji, Y.; Shin, J.S.; Lee, S.; Lee, S.H. Venom peptides from solitary hunting wasps induce feeding disorder in lepidopteran larvae. Peptides 2011, 32, 568-572. [CrossRef] [PubMed]

106. Ye, J.; Zhao, H.; Wang, H.; Bian, J.; Zheng, R. A defensin antimicrobial peptide from the venoms of Nasonia vitripennis. Toxicon 2010, 56, 101-106. [CrossRef] [PubMed]

107. Lopes, K.S.; Campos, G.A.A.; Camargo, L.C.; de Souza, A.C.B.; Ibituruna, B.V.; Magalhães, A.C.M.; da Rocha, L.F.; Garcia, A.B.; Rodrigues, M.C.; Ribeiro, D.M.; et al. Characterization of two peptides isolated from the venom of social wasp Chartergellus communis (Hymenoptera: Vespidae): Influence of multiple alanine residues and C-terminal amidation on biological effects. Peptides 2017, 95, 84-93. [CrossRef]

108. Montana, V.; Sontheimer, H. Bradykinin promotes the chemotactic invasion of primary brain tumors. J. Neurosci. 2011, 31, 4858-4867. [CrossRef] [PubMed]

109. Yasuhara, T.; Mantel, P.; Nakajima, T.; Piek, T. Two kinins isolated from an extract of the venom reservoirs of the solitary wasp Megascolia flavifrons. Toxicon 1987, 25, 527-535. [CrossRef]

110. Mortari, M.R.; Cunha, A.O.S.; Carolino, R.O.G.; Coutinho-Netto, J.; Tomaz, J.C.; Lopes, N.P.; Coimbra, N.C.; Dos Santos, W.F. Inhibition of acute nociceptive responses in rats after i.c.v. injection of Thr 6-bradykinin, isolated from the venom of the social wasp, Polybia occidentalis. Br. J. Pharmacol. 2007, 151, 860-869. [CrossRef] [PubMed]

111. Picolo, G.; Hisada, M.; Moura, A.B.; Machado, M.F.M.; Sciani, J.M.; Conceição, I.M.; Melo, R.L.; Oliveira, V.; Lima-Landman, M.T.R.; Cury, Y.; et al. Bradykinin-related peptides in the venom of the solitary wasp Cyphononyx fulvognathus. Biochem. Pharmacol. 2010, 79, 478-486. [CrossRef]

112. Silva, J.C.; Neto, L.M.; Neves, R.C.; Gonçalves, J.C.; Trentini, M.M.; Mucury-filho, R.; Smidt, K.S.; Fensterseifer, I.C.; Silva, O.N.; Lima, L.D.; et al. Evaluation of the antimicrobial activity of the mastoparan Polybia-MPII isolated from venom of the social wasp Pseudopolybia vespiceps testacea (Vespidae, Hymenoptera). Int. J. Antimicrob. Agents 2017, 49, 167-175. [CrossRef]

113. Tuichibaev, M.U.; Tashmukhamedov, B.A. Lysophospholipase activity of orientotoxin from the venom of the hornet Vespa orientalis. Chem. Nat. Compd. 1996, 20, 765-766. [CrossRef]

114. Tuı̆chibaev, M.U.; Tashmukhamedov, B.A.; Gotgil'f, I.G.; Mazannik, L.G. Orientotoxin-a new presynaptic neurotoxin from the venom of the giant hornet Vespa orientalis. Bioorg. Khim. 1984, 10, 318-322. [PubMed] 
115. L'vov, V.M.; Kolmakova, A.A.; Akhunov, A.A.; Mukhamedov, I.F. Vasoactive peptides from venom of the hornet Vespa orientalis physiochemical and functional characterization. Chem. Nat. Compd. 1988, 24, 218-221. [CrossRef]

116. Moore, E.L.; Arvidson, R.; Banks, C.; Urenda, J.P.; Duong, E.; Mohammed, H.; Adams, M.E. Ampulexins: A new family of peptides in venom of the emerald jewel wasp, Ampulex compressa. Biochemistry 2018, 57, 1907-1916. [CrossRef]

117. Turillazzi, S.; Mastrobuoni, G.; Dani, F.R.; Moneti, G.; Pieraccini, G.; La Marca, G.; Bartolucci, G.; Perito, B.; Lambardi, D.; Cavallini, V.; et al. Dominulin A and B: Two new antibacterial peptides identified on the cuticle and in the venom of the social paper wasp Polistes dominulus using MALDI-TOF, MALDI-TOF/TOF, and ESI-ion trap. J. Am. Soc. Mass Spectrom. 2006, 17, 376-383. [CrossRef]

118. Mendes, M.A.; Palma, M.S. Two new bradykinin-related peptides from the venom of the social wasp Protopolybia exigua (Saussure). Peptides 2006, 27, 2632-2639. [CrossRef] [PubMed]

119. Ombati, R.; Wang, Y.; Du, C.; Lu, X.; Li, B.; Nyachieo, A.; Li, Y.; Yang, S.; Lai, R. A membrane disrupting toxin from wasp venom underlies the molecular mechanism of tissue damage. Toxicon 2018, 148, 56-63. [CrossRef]

120. Yshii, L.M.; Souza, G.H.M.F.; Camargo, E.A.; Eberlin, M.N.; Ribela, M.T.C.P.; Muscará, M.N.; Hyslop, S.; Costa, S.K.P. Characterization of the mechanisms underlying the inflammatory response to Polistes lanio lanio (paper wasp) venom in mouse dorsal skin. Toxicon 2009, 53, 42-52. [CrossRef]

121. Zhou, S.T.; Luan, K.; Ni, L.L.; Wang, Y.; Yuan, S.M.; Che, Y.H.; Yang, Z.Z.; Zhang, C.G.; Yang, Z. Bin A strategy for quality control of vespa magnifica (Smith) venom based on HPLC fingerprint analysis and multi-component separation combined with quantitative analysis. Molecules 2019, 24, 2920. [CrossRef]

122. Hernández, C.; Konno, K.; Salceda, E.; Vega, R.; Zaharenko, A.J.; Soto, E. Sa12b peptide from solitary wasp inhibits ASIC currents in rat dorsal root ganglion neurons. Toxins 2019, 11, 585. [CrossRef] [PubMed]

123. Freire, D.O.; da Cunha, N.B.; Leite, M.L.; Kostopoulos, A.G.C.; da Silva, S.N.B.; de Souza, A.C.B.; Nolasco, D.O.; Franco, O.L.; Mortari, M.R.; Dias, S.C. Wasp venom peptide, synoeca-MP, from Synoeca surinama shows antimicrobial activity against human and animal pathogenic microorganisms. Pept. Sci. 2020, 112, e24141. [CrossRef]

124. Yang, H.; Xu, X.; Ma, D.; Zhang, K.; Lai, R. A phospholipase A1 platelet activator from the wasp venom of Vespa magnifica (Smith). Toxicon 2008, 51, 289-296. [CrossRef] [PubMed]

125. Santos, L.D.; Santos, K.S.; de Souza, B.M.; Arcuri, H.A.; Cunha-Neto, E.; Castro, F.M.; Kalil, J.E.; Palma, M.S. Purification, sequencing and structural characterization of the phospholipase A1 from the venom of the social wasp Polybia paulista (Hymenoptera, Vespidae). Toxicon 2007, 50, 923-937. [CrossRef]

126. Aoki, J.; Inoue, A.; Makide, K.; Saiki, N.; Arai, H. Structure and function of extracellular phospholipase A1 belonging to the pancreatic lipase gene family. Biochimie 2007, 89, 197-204. [CrossRef] [PubMed]

127. Liu, N.-Y.; Xu, Z.-W.; Yan, W.; Ren, X.-M.; Zhang, Z.-Q.; Zhu, J.-Y. Venomics reveals novel ion transport peptide-likes (ITPLs) from the parasitoid wasp Tetrastichus brontispae. Toxicon 2018, 141, 88-93. [CrossRef]

128. De Oliveira, M.R.; Palma, M.S. Polybitoxins: A group of phospholipases A2 from the venom of the neotropical social wasp paulistinha (Polybia paulista). Toxicon 1998, 36, 189-199. [CrossRef]

129. Mueller, U.; Elliott, W.; Reisman, R.; Ishay, J.; Walsh, S.; Steger, R.; Wypych, J.; Arbesman, C. Comparison of biochemical and immunologic properties of venoms from four hornet species. J. Allergy Clin. Immunol. 1981, 67, 290-298. [CrossRef]

130. Allalouf, D.; Ber, A.; Ishay, J. Hyaluronidase activity of extracts of venom sacs of a number of vespinae (Hymenoptera). Comp. Biochem. Physiol._Part B Biochem. 1972, 43, 119-123. [CrossRef]

131. Rungsa, P.; Incamnoi, P.; Sukprasert, S.; Uawonggul, N.; Klaynongsruang, S.; Daduang, J.; Patramanon, R.; Roytrakul, S.; Daduang, S. Cloning, structural modelling and characterization of VesT2s, a wasp venom hyaluronidase (HAase) from Vespa tropica. J. Venom. Anim. Toxins Incl. Trop. Dis. 2016, 22, 1-11. [CrossRef]

132. Bernheimer, A.W.; Avigad, L.S.; Schmidt, J.O.; Ishay, J.S. Proteins in venoms of two wasps, Polistes comanchus navajoe and Vespa orientalis. Comp. Biochem. Physiol. Part C Comp. Pharmacol. 1982, 71, 203-207. [CrossRef]

133. Arcuri, H.A.; Kalil, J.E.; Palma, M.S. Using proteomic strategies for sequencing and post-translational modifications assignment of antigen-5, a major allergen from the venom of the social wasp Polybia paulista. J. Proteome Res. 2013, 13, 855-865.

134. Yamamoto, T.; Arimoto, H.; Kinumi, T.; Oba, Y.; Uemura, D. Identification of proteins from venom of the paralytic spider wasp, Cyphononyx dorsalis. Insect Biochem. Mol. Biol. 2007, 37, 278-286. [CrossRef]

135. Wu, M.; Ye, G.; Zhu, J.; Chen, X.; Hu, C. Isolation and characterization of an immunosuppressive protein from venom of the pupa-specific endoparasitoid Pteromalus puparum. J. Invertebr. Pathol. 2008, 99, 186-191. [CrossRef]

136. Asgari, S.; Zareie, R.; Zhang, G.; Schmidt, O. Isolation and characterization of a novel venom protein from an endoparasitoid, Cotesia rubecula (Hym: Braconidae). Arch. Insect Biochem. Physiol. 2003, 53, 92-100. [CrossRef] [PubMed]

137. Han, J.; You, D.; Xu, X.; Han, W.; Lu, Y.; Lai, R.; Meng, Q. An anticoagulant serine protease from the wasp venom of Vespa magnifica. Toxicon 2008, 51, 914-922. [CrossRef]

138. Thiéry, D.; Bonnard, O.; Riquier, L.; De Revel, G.; Monceau, K. An alarm pheromone in the venom gland of Vespa velutina: Evidence revisited from the European invasive population. Entomol. Gen. 2018, 38, 145-156. [CrossRef]

139. Elmquist, D.C.; Landolt, P.J.; Cooper, W.R.; Reed, H.; Foutz, J.; Clepper, T.; Kacprzyk, B.; Teig, D.; Zack, R.S. The venom compound $\mathrm{N}$-(3-methylbutyl) acetamide attracts several Polistes (Fuscopolistes) Species (Hymenoptera: Vespidae). J. Econ. Entomol. 2020, 113, 1073-1079. [CrossRef] [PubMed] 
140. Dani, F.R.; Jeanne, R.L.; Clarke, S.R.; Jones, G.R.; Morgan, E.D.; Francke, W.; Turillazzi, S. Chemical characterization of the alarm pheromone in the venom of Polybia occidentalis and of volatiles from the venom of P. sericea. Physiol. Entomol. 2000, 25, 363-369. [CrossRef]

141. Lateef, A.; Ojo, S.A.; Elegbede, J.A. The emerging roles of arthropods and their metabolites in the green synthesis of metallic nanoparticles. Nanotechnol. Rev. 2016, 5, 601-622. [CrossRef]

142. Lateef, A.; Akande, M.A.; Ojo, S.A.; Folarin, B.I.; Gueguim-Kana, E.B.; Beukes, L.S. Paper wasp nest-mediated biosynthesis of silver nanoparticles for antimicrobial, catalytic, anticoagulant, and thrombolytic applications. 3 Biotech 2016, 6, 140. [CrossRef]

143. Chugh, A.; Eudes, F.; Shim, Y. Cell-penetrating peptides: Nanocarrier for macromolecule delivery in living cells. IUBMB Life 2010, 62, 183-193. [CrossRef]

144. Zhang, C.; Ren, W.; Liu, Q.; Tan, Z.; Li, J.; Tong, C. Transportan-derived cell-penetrating peptide delivers siRNA to inhibit replication of influenza virus in vivo. Drug Des. Devel. Ther. 2019, 13, 1059. [CrossRef]

145. Schiener, M.; Graessel, A.; Ollert, M.; Schmidt-Weber, C.B.; Blank, S. Allergen-specific immunotherapy of Hymenoptera venom allergy-also a matter of diagnosis. Hum. Vaccines Immunother. 2017, 13, 2467-2481. [CrossRef] [PubMed]

146. Chai, L.; Yang, X.; Liu, M.; Liu, C.; Han, L.; Guo, H.; Li, C.; Sun, Y.; Li, X.; Xiao, M.; et al. Biopanning of allergens from wasp sting patients. Biosci. Rep. 2018, 38, BSR20181113-BSR20181129. [CrossRef]

147. Lâm, H.T.; Ekerljung, L.; Bjerg, A.; Vschwan Tuong, N.; Lundback, B.; Ronmark, E. Sensitization to airborne allergens among adults and its impact on allergic symptoms: A population survey in northern Vietnam. Clin. Transl. Allergy 2014, 4, 6. [CrossRef]

148. Charpin, D.; Birnbaum, J.; Vervloet, D. Epidemiology of Hymenoptera allergy. Clin. Exp. Allergy 1994, 24, 1010-1015. [CrossRef] [PubMed]

149. Boz, C.; Velioglu, S.; Ozmenoglu, M. Acute disseminated encephalomyelitis after bee sting. Neurol. Sci. 2003, $23,313-315$. [CrossRef] [PubMed]

150. Bonifazi, F.; Jutel, M.; Biló, B.M.; Birnbaum, J.; Muller, U. Prevention and treatment of hymenoptera venom allergy: Guidelines for clinical practice. Allergy 2005, 60, 1459-1470. [CrossRef] [PubMed]

151. Bilo, F.; Bonifazi, B.M. Epidemiology of insect venom anaphylaxis. Curr. Opin. Allergy Clin. Immunol. 2008, 8, 330-337. [CrossRef] [PubMed]

152. Hoffman, D.R. Allergens in Hymenoptera venom XV: The immunologic basis of vespid venom cross-reactivity. J. Allergy Clin. Immunol. 1985, 75, 611-613. [CrossRef]

153. Bilo, B.M.; Rueff, F.; Mosbech, H.; Bonifazi, F.; Oude-Elberink, J.N.G.; Hypersensitivity, E.I.G. on I.V. Diagnosis of Hymenoptera venom allergy. Allergy 2005, 60, 1339-1349. [CrossRef]

154. An, S.; Chen, L.; Wei, J.-F.; Yang, X.; Ma, D.; Xu, X.; Xu, X.; He, S.; Lu, J.; Lai, R. Purification and characterization of two new allergens from the venom of Vespa magnifica. PLoS ONE 2012, 7, e31920-e31926. [CrossRef] [PubMed]

155. Bazon, M.L.; Silveira, L.H.; Simioni, P.U.; Brochetto-Braga, M.R. Current advances in immunological studies on the vespidae venom antigen 5: Therapeutic and prophylaxis to hypersensitivity responses. Toxins 2018, 10, 305. [CrossRef] [PubMed]

156. Bazon, M.L.; Perez-Riverol, A.; Dos Santos-Pinto, J.R.A.; Fernandes, L.G.R.; Lasa, A.M.; Justo-Jacomini, D.L.; Palma, M.S.; De Lima Zollner, R.; Brochetto-Braga, M.R. Heterologous expression, purification and immunoreactivity of the antigen 5 from Polybia paulista wasp venom. Toxins 2017, 9, 259. [CrossRef] [PubMed]

157. Dos Santos, L.D.; Santos, K.S.; Pinto, J.R.A.; Dias, N.B.; De Souza, B.M.; Dos Santos, M.F.; Perales, J.; Domont, G.B.; Castro, F.M.; Kalil, J.E.; et al. Profiling the proteome of the venom from the social wasp Polybia paulista: A clue to understand the envenoming mechanism. J. Proteome Res. 2010, 9, 3867-3877. [CrossRef]

158. Peternelj, A.; Silar, M.; Bajrovic, N.; Adamic, K.; Music, E.; Kosnik, M.; Korosec, P. Diagnosis of venom allergy by flow cytometry. Correction with clinical history, skin tests, specific IgE, histamine and leukotriene C4 release. Clin. Exp. Allergy 2000, 30, $1166-1171$.

159. Eberlein, B.; Krischan, L.; Darsow, U.; Ollert, M.; Ring, J. Double positivity to bee and wasp venom: Improved diagnostic procedure by recombinant allergen-based IgE testing and basophil activation test including data about cross-reactive carbohydrate determinants. J. Allergy Clin. Immunol. 2012, 130, 155-161. [CrossRef]

160. Gattinger, P.; Lupinek, C.; Kalogiros, L.; Silar, M.; Zidarn, M.; Korosec, P.; Koessler, C.; Novak, N.; Valenta, R.; Mittermann, I. The culprit insect but not severity of allergic reactions to bee and wasp venom can be determined by molecular diagnosis. PLoS ONE 2018, 13, e0199250. [CrossRef]

161. Peternelj, A.; Silar, M.; Bajrovic, N.; Adamic, K.; Music, E.; Kosnik, M.; Korosec, P. Diagnostic value of the basophil activation test in evaluating Hymenoptera venom sensitization. Wien. Klin. Wochenschr. 2009, 12, 334-348. [CrossRef]

162. Sturm, G.J.; Heinemann, A.; Schuster, C.; Wiednig, M.; Groselj-Strele, A.; Sturm, E.M.; Aberer, W. Ifluence of total IgE levels on severity on sting reactions in hymenoptera venom allergy. Allergy 2007, 62, 884-889. [CrossRef]

163. Balzer, L.; Pennino, D.; Blank, S.; Seismann, H.; Darsow, U.; Schnedler, M.; McIntyre, M.; Ollert, M.W.; Durham, S.R.; Spillner, E.; et al. Basophil activation test using recombinant allergens: Highly specific diagnostic method complementing routine tests in wasp venom allergy. PLoS ONE 2014, 9, e108619. [CrossRef] [PubMed]

164. Tomsitz, D.; Brockow, K. Component resolved diagnosis in Hymenoptera anaphylaxis. Curr. Allergy Asthma Rep. 2017, 17, 38-46. [CrossRef] [PubMed] 
165. Perez-Riverol, A.; Musacchio-Lasa, A.; Fernandes, L.G.R.; dos Santos-Pinto, J.R.A.; Esteves, F.G.; Bazon, M.L.; de Lima Zollner, R.; Palma, M.S.; Brochetto-Braga, M.R. Improved production of the recombinant phospholipase A1 from Polybia paulista wasp venom expressed in bacterial cells for use in routine diagnostics. 3 Biotech 2020, 10, 217-228. [CrossRef]

166. Kołaczek, A.; Skorupa, D.; Antczak-Marczak, M.; Kuna, P.; Kupczyk, M. Safety and efficacy of venom immunotherapy: A real life study. Postep. Dermatol. Alergol. 2017, 34, 159-167. [CrossRef]

167. Köhli-Wiesner, A.; Stahlberger, L.; Bieli, C.; Stricker, T.; Lauener, R. Induction of specific immunotherapy with hymenoptera venoms using ultrarush regimen in children: Safety and tolerance. J. Allergy 2011, 2012, 1-5. [CrossRef] [PubMed]

168. Perez-Riverol, A.; Fernandes, L.G.R.; Musacchio Lasa, A.; dos Santos-Pinto, J.R.A.; Moitinho Abram, D.; Izuka Moraes, G.H.; Jabs, F.; Miehe, M.; Seismman, H.; Palma, M.S.; et al. Phospholipase A1-based cross-reactivity among venoms of clinically relevant Hymenoptera from Neotropical and temperate regions. Mol. Immunol. 2018, 93, 87-93. [CrossRef] [PubMed]

169. Jappe, U.; Raulf-Heimsoth, M.; Hoffmann, M.; Burow, G.; Hübsch-Müller, C.; Enk, A. In vitro hymenoptera venom allergy diagnosis: Improved by screening for cross-reactive carbohydrate determinants and reciprocal inhibition. Allergy 2006, 61, 1220-1229. [CrossRef] [PubMed]

170. Schiener, M.; Eberlein, B.; Moreno-Aguilar, C.; Pietsch, G.; Serrano, P.; McIntyre, M.; Schwarze, L.; Russkamp, D.; Biedermann, T.; Spillner, E.; et al. Application of recombinant antigen 5 allergens from seven allergy-relevant Hymenoptera species in diagnostics. Allergy Eur. J. Allergy Clin. Immunol. 2017, 72, 98-108. [CrossRef]

171. Holt, P.G.; Macaubas, C.; Stumbles, P.A.; Sly, P.D. The role of allergy in the development of asthma. Nature 1999, 402, 12-17. [CrossRef]

172. Seyfarth, F.; Schliemann, S. Diagnostic precision of component-resolved vs. extract-based in vitro diagnosis of Hymenoptera venom allergy: Effects on clinical management. J. Ger. Soc. Dermatol. 2017, 15, 507-515. [CrossRef] [PubMed]

173. Yoshida, N.; Hirata, H.; Watanabe, M.; Sugiyama, K.; Arima, M.; Fukushima, Y.; Ishii, Y. Improved sensitivity to venom specificimmunoglobulin E by spiking with the allergen component in Japanese patients suspected of Hymenoptera venom allergy. Allergol. Int. 2015, 64, 248-252. [CrossRef] [PubMed]

174. Mosbech, H.; Malling, H.; Biering, I.; Böwadt, H.; Søborg, M.; Weeke, B.; Løwenstein, H. Immunotherapy with yellow jacket venom: A comparative study including three different extracts, one adsorbed to aluminium hydroxide and two unmodified. Allergy 1986, 41, 95-103. [CrossRef] [PubMed]

175. Bilò, M.B.; Antonicelli, L.; Bonifazi, F. Purified vs. nonpurified venom immunotherapy. Curr. Opin. Allergy Clin. Immunol. 2010, 10, 330-336. [CrossRef] [PubMed]

176. Drug Bank. Available online: https:/ / www.drugbank.ca/drugs/DB11029 (accessed on 19 January 2021).

177. Drug Bank. Available online: https://www.drugbank.ca/drugs/DB11028 (accessed on 19 January 2021).

178. Drug Bank. Available online: https:/ / www.drugbank.ca/drugs/DB11030 (accessed on 19 January 2021).

179. Drug Bank. Available online: https:/ / go.drugbank.com/drugs/DB10959 (accessed on 19 January 2021).

180. Drug Bank. Available online: https:/ / www.drugbank.ca/drugs/DB11033 (accessed on 19 January 2021).

181. Drug Bank. Available online: https:/ / www.drugbank.ca/drugs/DB10957 (accessed on 19 January 2021).

182. Drug Bank. Available online: https:/ / www.drugbank.ca/drugs/DB10958 (accessed on 19 January 2021).

183. Drug Bank. Available online: https:/ / www.drugbank.ca/drugs/DB11031 (accessed on 19 January 2021).

184. Drug Bank. Available online: https:/ / www.drugbank.ca/drugs/DB10956 (accessed on 19 January 2021). 